\title{
Kinetic Modeling Study on the Combustion Characterization of Synthetic C3 and C4 Alcohols for Lean Premixed Prevaporized Combustion
}

\author{
Solmaz Nadiri ${ }^{1,2, *}$, Paul Zimmermann ${ }^{2,3}$, Laxmi Sane ${ }^{1,2}$, Ravi Fernandes ${ }^{1,2}$, Friedrich Dinkelacker ${ }^{2,3}$ \\ and Bo Shu ${ }^{1,2} \mathbb{B}$ \\ 1 Department of Physical Chemistry, Physikalisch-Technische Bundesanstalt 100, \\ 38116 Braunschweig, Germany; laxmi.sane@ptb.de (L.S.); ravi.fernandes@ptb.de (R.F.); \\ bo.shu@ptb.de (B.S.) \\ 2 Cluster of Excellence SE2A-Sustainable and Energy-Efficient Aviation, Technische Universität \\ Braunschweig, 38106 Braunschweig, Germany; zimmermann@itv.uni-hannover.de (P.Z.); \\ dinkelacker@itv.uni-hannover.de (F.D.) \\ 3 Institute of Technical Combustion, Leibniz University Hannover, An der Universität 1, \\ 30823 Garbsen, Germany \\ * Correspondence: Solmaz.nadiri@ptb.de
}

check for updates

Citation: Nadiri, S.; Zimmermann, P.; Sane, L.; Fernandes, R.; Dinkelacker, F.; Shu, B. Kinetic Modeling Study on the Combustion Characterization of Synthetic C3 and C4 Alcohols for Lean Premixed Prevaporized Combustion. Energies 2021, 14, 5473. https://doi.org/10.3390/en14175473

Academic Editors: Matteo Pelucchi and Liming Cai

Received: 23 July 2021

Accepted: 30 August 2021

Published: 2 September 2021

Publisher's Note: MDPI stays neutral with regard to jurisdictional claims in published maps and institutional affiliations.

Copyright: (c) 2021 by the authors. Licensee MDPI, Basel, Switzerland. This article is an open access article distributed under the terms and conditions of the Creative Commons Attribution (CC BY) license (https:/ / creativecommons.org/licenses/by/ $4.0 /)$.

\begin{abstract}
To reach sustainable aviation, one approach is to use electro-fuels (e-fuels) within the gas turbine engines. E-fuels are $\mathrm{CO}_{2}$-neutral synthetic fuels which are produced employing electrical energy generated from renewable resources, where the carbon is taken out of the atmosphere or from biomass. Our approach is, to find e-fuels, which can be utilized in the lean premixed prevaporized (LPP) combustion, where most of the non- $\mathrm{CO}_{2}$ emissions are prevented. One of the suitable e-fuel classes is alcohols with a low number of carbons. In this work, the autoignition properties of propanol isomers and butanol isomers as e-fuels were investigated in a high-pressure shock tube (HPST) at temperatures from 1200 to $1500 \mathrm{~K}$, the pressure of $10 \mathrm{bar}$, and lean fuel-air conditions. Additional investigations on the low-temperature oxidation and flame speed of C3 and C4 alcohols from the literature were employed to develop a comprehensive mechanism for the prediction of ignition delay time (IDT) and laminar burning velocity (LBV) of the above-mentioned fuels. A numerical model based on newly developed chemical kinetics was applied to further study the IDT and LBV of fuels in comparison to the Jet-A surrogate at the engine-related conditions along with the emissions prediction of the model at lean fuel-air conditions.
\end{abstract}

Keywords: lean premixed prevaporized; e-fuels; ignition delay time; laminar burning velocity; chemical kinetic modeling

\section{Introduction}

As the air traffic has increased over the last decades it has led to the rise of carbon dioxide $\left(\mathrm{CO}_{2}\right)$ emissions. Aviation contributes to about $3.2 \%$ of the global anthropogenic $\mathrm{CO}_{2}$ emissions which tends to increase [1,2]. The European Commission has implied strict regulations to mitigate the $\mathrm{CO}_{2}$ emission from aviation and has adopted proposals to reduce net greenhouse gas emissions by at least $55 \%$ by 2030 [3].

Hence, future aviation concepts should be designed to reduce $\mathrm{CO}_{2}$ emissions. However, for this transition to succeed, significant issues related to renewable energy must be addressed. This has stimulated active research with an increase in interest towards a renewable form of energy in the last decade. One promising strategy which reduces emissions such as $\mathrm{CO}_{2}, \mathrm{NOx}$, and enhances sustainable aviation, is the introduction of Electro-fuels (e-fuels) which are carbon-neutral synthetic fuels. E-Fuels are produced by converting electrical energy into chemical bonds applying the Power-to- " $\mathrm{X}^{\prime \prime}(\mathrm{PtX})$ technology, in which the electrical power is generated from a renewable power source in form 
of wind or solar energy and the $\mathrm{X}$ components are chemical energy carriers in the form of liquid or gas [4]. PtX technology can be used to produce value-added fuels from $\mathrm{CO}_{2}$ using various electrification and hydrogenation methods $[5,6]$.

As an alternative to fossil jet fuels, the Power-to-Liquid ( $\mathrm{PtL}$ ) technology could be used to produce synthetic kerosene [7]. This approach leads to a "drop-in" fuel, which has the advantage to be operable within the existing airplane fleet with only slight modifications. Additionally, a stepwise transition to such $\mathrm{CO}_{2}$-neutral fuel application is possible, as this fuel can be mixed into the existing fossil kerosene.

However, also non- $\mathrm{CO}_{2}$ emissions like nitrogen oxides and particles have a significant impact on the greenhouse gas effect and the environment. According to recent studies on the environmental impact of emissions within the higher atmosphere, the non- $\mathrm{CO}_{2}$ emissions from nitrogen oxides and particles in conjunction with the emitted water molecules and its influence on contrail formation in typical flight levels is seen to be about twice the influence on that of the $\mathrm{CO}_{2}$ emission by itself [8,9]. Here only the radiative forcing influence on the greenhouse gas effect is regarded. Additionally, other influences of these emissions might be of importance, for instance on the ozone layer depletion in the higher atmosphere. With that, it can be concluded that the replacement of fossil kerosene with synthetically produced E-kerosene leads to a strong reduction of the $\mathrm{CO}_{2}$ emission by itself, but only to a weak reduction of around 30 percent or less to the overall greenhouse gas effect.

Our approach is instead to find other e-fuels, which can be utilized in the lean premixed prevaporized (LPP) burning approach, where all particle emission and most of the nitrogen oxide emission is prevented [10]. This lower NOx emission is due to the lower flame temperature at lean fuel-air condition. The LPP combustion approach has been proposed in the past by several researchers. However, it has been investigated with the use of conventional, fossil fuels, such as Jet A1 and kerosene, primarily consisting of long-chained hydrocarbons and cyclo-alkanes [11,12]. These lead to pre-ignition and flashback due to their high reactivity, causing major issues in terms of flame stability and therefore safety. Instead, we search for suitable e-fuel classes, where the self-ignition tendency and the danger of flashbacks are strongly reduced [10].

Compared to other candidates, alcohols such as propanol and butanol have more potential which could be used to replace conventional fuels [2,13] such as jet-fuels (kerosene) or as additives for gasoline and diesel [14-16]. Propanol and butanol have an isomeric structure such as n-propanol $\left(\mathrm{CH}_{3} \mathrm{CH}_{2} \mathrm{CH}_{2} \mathrm{OH}\right)$, iso-propanol $\left(\mathrm{CH}_{3} \mathrm{CH}(\mathrm{OH}) \mathrm{CH}_{3}\right)$, n-butanol $\left(\mathrm{CH}_{3} \mathrm{CH}_{2} \mathrm{CH}_{2} \mathrm{CH}_{2} \mathrm{OH}\right)$, sec-butanol $\left(\mathrm{CH}_{3} \mathrm{CH}(\mathrm{OH}) \mathrm{CH}_{2} \mathrm{CH}_{3}\right)$, iso-butanol $\left(\left(\mathrm{CH}_{3}\right)_{2} \mathrm{CHCH}_{2} \mathrm{OH}\right)$ and tert-butanol $\left(\left(\mathrm{CH}_{3}\right)_{3} \mathrm{COH}\right)$, respectively. In addition, they have quite attractive physicalchemical properties such as a high energy density of about $24 \mathrm{MJ} / \mathrm{L}$ and $27.76 \mathrm{MJ} / \mathrm{L}$, respectively. The higher oxygen content of these fuels can reduce soot formation promoting cleaner combustion [13]. Moreover, propanol and butanol isomers have higher polarity, octane rating and low vapor pressure as compared to methanol and ethanol which reduces emissions due to evaporation and the possible chance of an explosion [17]. Taking into account the thermodynamic properties such as latent heat of vaporization, there is a reduction in the overall combustion temperature hence leading to a reduction in NOx emissions [18]. Therefore, propanol and butanol isomers are targeted fuels in this study.

From this point of view, the LPP combustion [19-21] is the most straightforward way to achieve lean conditions by premixing the fuel and air, which meets the needs of clean power generation and lowering of emissions such as soot, $\mathrm{CO}_{2}$, and NOx [22]. The LPP combustion has always provided the promise of obtaining low pollutant emissions while burning liquid fuels. In this approach, a lean condition is considered where there is a higher volume of air and a lower volume of fuel in the mix. The engines designed for lean-burning can employ higher compression ratios and thus provide a better performance, efficient fuel use and low exhaust hydrocarbon emissions than those found in conventional gasoline engines [19]. Hence it is our approach that LPP combustion with e-fuels can 
ensure sustainable aviation with much lower environmental impact than the replacement approach of fossil kerosene with synthetically produced e-kerosine.

To understand the potential of the fuels, the key properties of their combustion such as ignition delay time (IDT) and laminar burning velocity (LBV) must be characterized. The IDT is a measure of how spontaneously ignition occurs. IDT is an important parameter for the validation of a chemical kinetic mechanism. Moreover, the LBV is a key parameter for the assessment of the fuel's tendency for flashbacks, as recently shown by Goldmann et al. [23].

The combustion properties of propanol isomers were mainly investigated in shock tubes (ST) and rapid compression machine (RCM) to study the chemical kinetics of fuels. Johnson et al. [24] measured IDTs of dilute mixtures of propanol isomers in a shock tube between 1350 and $2000 \mathrm{~K}$ and pressure of $1 \mathrm{~atm}$, and it was found that n-propanol has higher reactivity than iso-propanol, which was well captured by their mechanism. It was observed from the model validation that the pathway for iso-propanol breakdown leads to a higher level through the dehydration reaction, lowering the chain-branching reaction and hence, increasing the ignition delay time (IDT) in comparison to n-propanol. Johnson et al. [24] proposed the primary chemical kinetic mechanism of propanol isomers on the basis of the C3-chemistry from Bourque et al. [25].

Man et al. [26] performed the IDT study of $n$ - and iso-propanol in an ST, under experimental conditions of 1100 and $1500 \mathrm{~K}$, at pressures from 1.2 to $16.0 \mathrm{~atm}$. It was observed that an increase in pressure, fuel concentration, and decreasing the equivalence ratio resulted in a decrease of IDTs. A detailed chemical kinetic mechanism was developed containing 238 species and 1448 reactions. The developed mechanism showed fairly good agreement with the experimentally determined IDTs. Moreover, additional validation of the developed kinetic mechanism was performed using LBV data, which also showed a reasonable agreement at the studied conditions. This mechanism was modified by Johnson et al. [24] on the basis of the analysis of Sarathy et al. [27] and Frassoldati et al. [28] to improve the prediction for the high-temperature IDTs. It was seen that the consumption of propanol is dominated by $\mathrm{H}$ - abstraction reactions resulting in the formation of products such as ethanol, ethene, propene, and acetone from respective isomers.

Frassoldati et al. [28] carried out an experimental study and modeling study of npropanol on the counterflow non-premixed flames, burner-stabilized premixed flames and in shock tubes, for temperature between 900 and $2000 \mathrm{~K}$. Gong et al. [29] performed a comparative study of n-propanol, propanal, acetone and propane in LBV. It was reported that n-propanol and propane possess similar LBV and the resulting $\mathrm{OH}$ and $\mathrm{H}$ radical concentrations.

Butanol combustion has been extensively studied compared to propanol as reported in the literature. Weber et al. [30] determined the IDTs in RCM at low temperature between 715 and $910 \mathrm{~K}$ and at high pressures of 15 and 30 bar and found that n-butanol followed by sec-butanol had low ignition delay times as compared to other isomers. Karwat et al. [31] conducted an experimental study on n-butanol using RCM in the temperature range of 920-1040 K and pressure of 2.86-3.35 bar, it observed that the IDTs showed no negative temperature coefficient (NTC) region hence were quite linear with Arrhenius scale. Heufer et al. [32] reported high-pressure IDT results for n-butanol/air mixtures behind the reflected shock at T: $770-1250 \mathrm{~K}, \phi=1$ and pressure range of $10-42$ bar. The results showed an interesting non-Arrhenius behavior at temperatures lower than $1000 \mathrm{~K}$ for the pressure range studied.

Moss et al. [17] conducted an experimental and kinetisc study for four isomers in the shock tube at T: $1200-1800 \mathrm{~K}$ and pressure: $1-4$ bar. According to the model, they found that there were three main pathways for the consumption of butanol, namely dehydration, uni-molecular decomposition, and $\mathrm{H}$-atom abstraction. They found that n-butanol was the most reactive followed by sec-butanol amongst the other isomers that were consumed primarily via dehydration. Stranic et al. [33] performed measurements in shock tube in the temperature range of 1050-1600 K and pressure of 1.5-43 bar for all four butanol isomers 
and a pre-ignition pressure rise in the n-butanol ignition below $1000 \mathrm{~K}$ was observed, which caused the non-Arrhenius behavior. These results were very similar to those reported by Weber et al. [30] and Heufer et al. [32].

There are only a few comparative experimental studies on the LBVs of the isomers of C3- and C4-alcohols. Veloo et al. [34,35] carried out comprehensive LBV measurements for all six isomers of propanol and butanol in the same experimental setup. Within these studies, the counterflow burner method is used at $343 \mathrm{~K}$ mixture temperature and atmospheric pressure for the range of equivalence ratio from 0.75 and 0.7 , respectively, to 1.5 .

Sarathy et al. [27] developed a mechanism to study the oxidation of butanol at both low and high temperatures with reaction rate constants according to rate rules. Recently Saggese et al. [36] developed and reduced the proposed mechanism by Sarathy and coworkers [27] to predict the oxidation of $n$ - and iso-propanol and butanol. The reaction rate constants of $\mathrm{H}$-atom abstraction by $\mathrm{OH}$, and $\mathrm{HO}_{2}$ in this mechanism were taken from McGillen et al. [37] and Mittal et al. [38], respectively. Among the different chemical kinetic mechanisms proposed in the literature, none of them can predict the IDT and LBV of all propanol and butanol isomers with high accuracy.

In this work, experimental data were measured for propanol and butanol isomers at the pressure of 10 bar and temperature of 1100 to $1500 \mathrm{~K}$ behind reflected shock waves covering the entire range of the LPP conditions which has been investigated for the first time. Moreover, a comprehensive universal mechanism was developed for propanol and butanol isomers. The mechanism was validated against HPST, RCM [39-41], and LBVs of the isomers of C3- and C4-alcohols by Veloo et al. [34,35]. In addition, numerical simulation on combustion properties such as IDT and LBV of butanol and propanol isomers in comparison to fuels such as Jet-A was performed at the gas turbine conditions to investigate the LPP combustion and determine the amount of soot precursors and NOx emission resulting from propanol and butanol oxidation.

\section{Materials and Methods}

\subsection{Experimental Setup}

The ignition delay experiments were performed in a high-pressure shock tube (HPST) at Physikalisch-Technische Bundesanstalt (PTB), Braunschweig, Germany. The HPST is built from stainless steel which has an overall inner diameter of $70 \mathrm{~mm}$ and a total length of $8 \mathrm{~m}$. The post-shock condition provided by the HPST is up to 1000 bar and $3000 \mathrm{~K}$. A vacuum pressure of $5 \times 10^{-5}$ mbar can be achieved in both driver and driven sections of the HPST using a turbo molecular pump (Leybold, Cologne, Germany). The butanol and propanol mixtures were prepared in a $50 \mathrm{~L}$ mixing tank, which uses a magnetic stirrer that homogenizes the mixture completely in about $1 \mathrm{~h}$. Argon gas obtained from Linde having the purity greater than $99.999 \%$ was used as bath gas in the HPST experiments. Oxygen is used as an oxidizer. The incident shock velocity at the end wall was determined by linear extrapolation of the velocity profile between the four piezoelectric pressure transducers (Kistler 603C) installed at equal distance along the last $2 \mathrm{~m}$ of the driven section. The pressure and temperature behind the reflected shock wave $\left(\mathrm{P}_{5}\right.$ and $\left.\mathrm{T}_{5}\right)$ were calculated using the 1-dimensional shock-wave equations [42]. Furthermore, another pressure sensor is installed at the center of the end flange which allows measuring the pressure behind the reflected shock wave, in turn, allows measuring the IDT. The overall uncertainty in IDT of about $5 \%$ was observed from the shock tube experiments which includes the uncertainty in the gas composition, initial state, and shock velocity. Each data point in the shock tube measurements were determined only once as it is nearly impossible to reproduce the formation of an incident shock wave with the same conditions. The six fuels namely n-propanol (Sigma-Aldrich, St. Louis, MO, USA, >99.9\%) iso-propanol (Sigma-Aldrich, $>99.9 \%$ ), n-butanol (Sigma-Aldrich, >99.5\%), sec-butanol (Sigma-Aldrich, >99.5\%), isobutanol (Sigma-Aldrich, $>99 \%$ ) and tert-butanol (Sigma-Aldrich, $>99.5 \%$ ) were studied under same conditions. 
As the experimental time in shock-tube is limited to $2 \mathrm{~ms}$ a highly responsive technique such as TDLAS was applied in this study. A quantum cascade CO laser (QCL) working at wavenumber of $2059.91 \mathrm{~cm}^{-1}$ was used as an ignition marker in determining the onset of ignition which was not clearly identified from the pressure rise as seen in Figure 1.

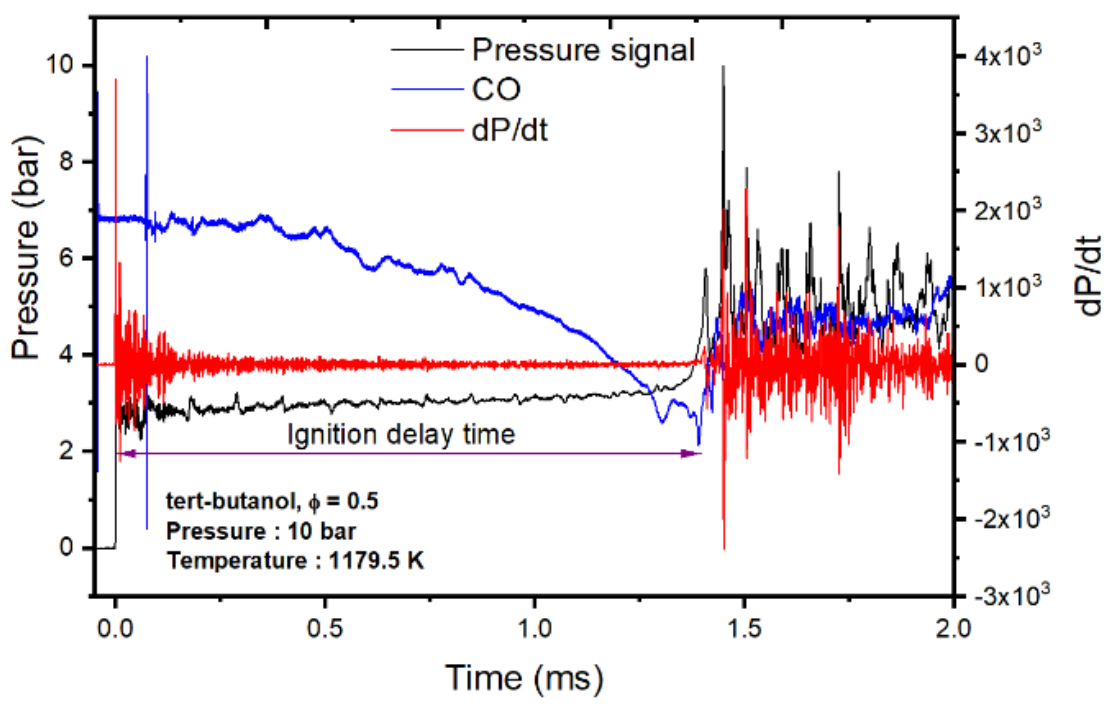

Figure 1. Typical pressure profile, pressure derivative $(\mathrm{dp} / \mathrm{dt})$ and $\mathrm{CO}$ absorption signal from a HPST experiment for tert-butanol.

Figure 2 represents the measured ignition delay times (IDTs) of propanol and butanol in the HPST at $1100-1500 \mathrm{~K}$, three equivalence ratios $0.9,0.5$, and 0.25 , at $90 \%$ dilution and pressure of 10 bar along with the linear fitted lines. In general, all measured IDTs at different conditions decrease monotonically with increasing temperatures and present a clear Arrhenius temperature dependence, which indicates that no NTC effect is observed in the investigated conditions. The IDTs of tert-butanol are apparently longer than the former ones and n-butanol has the shortest IDTs, and tert-butanol shows higher activation energy than other butanol isomers and both propanol isomers at all equivalence ratios, whereas n-butanol has the lowest activation energy compared with other targeted fuels. The order of the reactivity among propanol and butanol isomers is consistent under all investigated conditions, namely, $\mathrm{n}$-butanol $>$ iso-butanol $\cong$ sec-butanol $>$ n-propanol $>$ iso-propanol $>$ tert-butanol. Moreover, the results of our experiments are in accordance with previous studies by Man et al. [26] and Stranic et al. [33] on IDT of propanol and butanol isomers, respectively.

\subsection{Numerical Method}

To simulate the ignition delay and the laminar burning velocity of the propanol and butanol isomers, an open-source package from the $\mathrm{C}++$ based CANTERA code [43] was employed in this study. The full details of the functions and the procedures to simulate the IDTs measured in HPST and RCM can be found in our previous work [44], so only a brief explanation and definitions will be given here.

The calculation of IDT obtained in the shock tube was performed employing the numerical simulation of a zero-dimensional homogeneous adiabatic reactor while the IDT is defined as the time between time zero and the time where the simulated temperature reached its maximum increase rate. For the IDT longer than $2 \mathrm{~ms}$, the dp/dt effect of the shock tube must be taken into account, to do so, the measured pressure profile between time zero to ignition onset was converted into a volume profile for the simulation. The volume after ignition onset was considered constant.

To simulate the IDT measured in RCM the OD homogeneous adiabatic reactor was applied as well, however, the heat loss effect during the RCM measurement must be considered. Therefore, the adiabatic core assumption [45] has been applied and the heat loss has been calculated by converting the pressure profiles of non-reactive mixtures into 
volume profiles. The simulated IDTs in RCM were defined as the time interval between the end of compression (EOC) and ignition time, where the derivative of the pressure profile in terms of time reaches the local maximum.

Brute force sensitivity analysis on the IDT was performed to ascertain the major elementary reactions at each specific condition. A negative sensitivity coefficient implies that increasing the rate coefficient of a specific reaction, facilitates the ignition event and the positive sensitivity coefficient induces the opposite effect [44].

Laminar flame speeds were taken from the literature and re-calculated to model a free flame, which is one-dimensional, freely propagating, and premixed. The transport model is set to mixture-averaged values, from which follows that Soret effect is disabled. The adaptive grid parameters are set to fixed values with slope $=0.3$ and curve $=0.2$. The simulated flame is a premixed flame, which is both close to LBV experiments and LPP conditions.

A

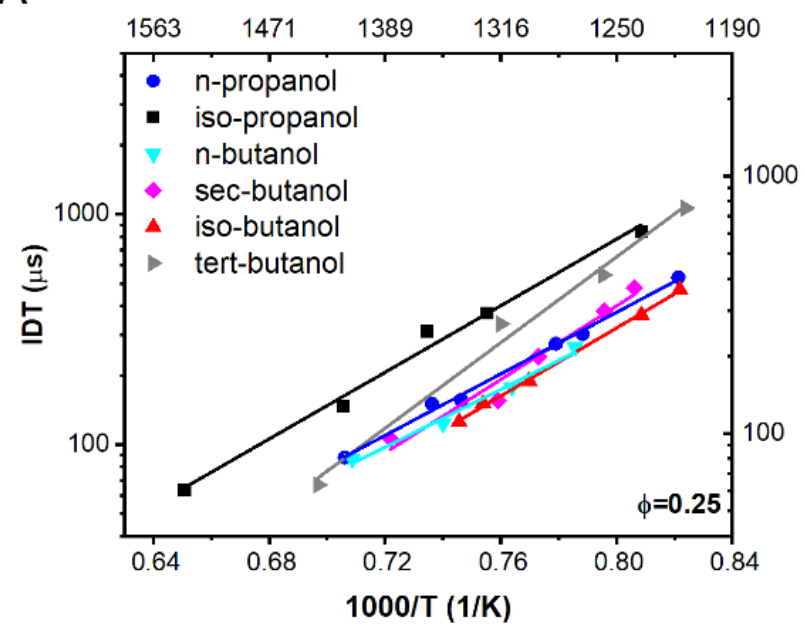

B

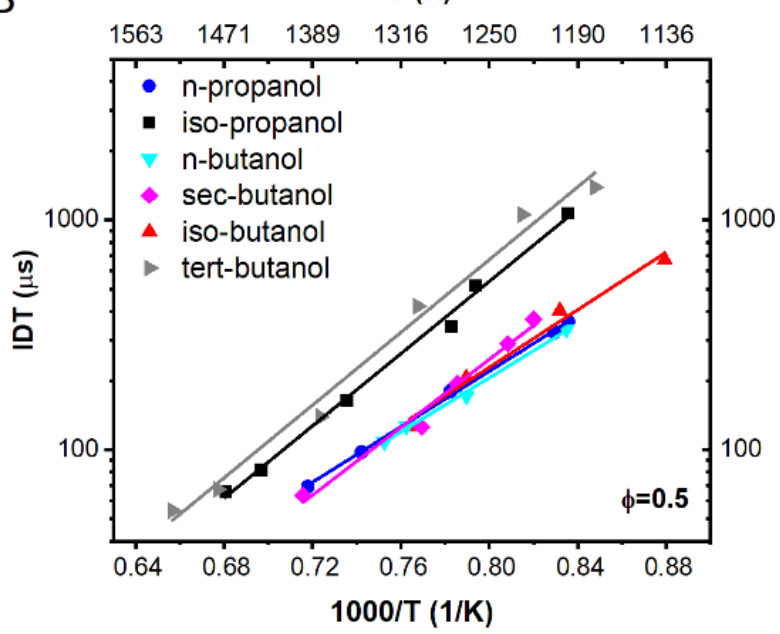

C $\mathbf{T}(\mathrm{K})$

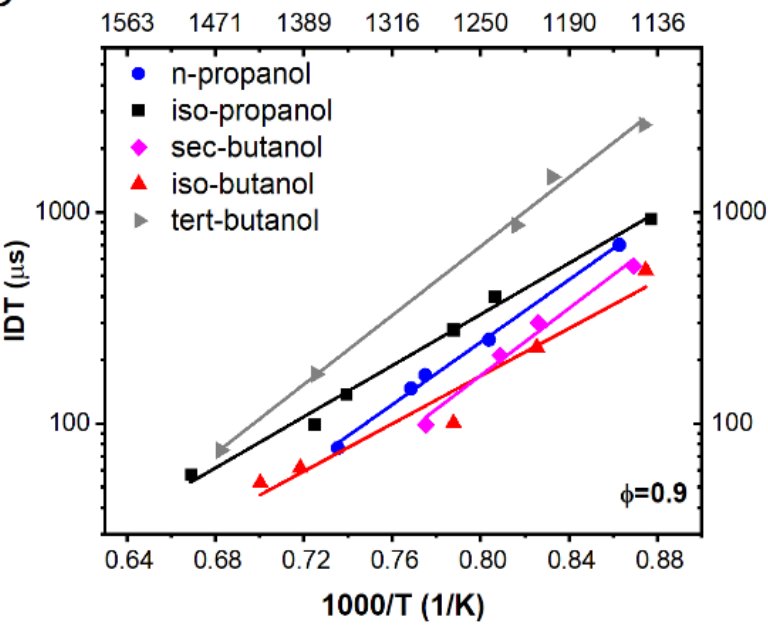

Figure 2. Ignition delay times (IDTs) of propanol and butanol isomers measured in this work in HPST at 10 bar, and (A) $\phi=0.25$, (B) 0.5 and (C) 0.9 .

\section{Results and Discussions}

\subsection{Literature Mechanisms Validation}

Recently, investigations on the ignition behavior of the propanol and butanol in RCM under the lean fuel-air conditions with equivalence ratios of $0.25,0.5$, and 0.9 with $90 \%$ dilution, temperatures between 750 and $980 \mathrm{~K}$, and pressures of 20 and 40 bar, were carried out in our group by Laguna [40] and Wang [39,41]. Wang [39,41] demonstrated that the 
Saggese2020 mechanism [36] shows the best performance for the prediction of IDTs of propanol isomers under the investigated conditions and the Van Geem mechanism [46] predicts IDTs of iso-butanol at 20 bar very well, while the Sarathy2012 [27] and Saggese2020 mechanisms show better performance at 40 bar. Furthermore, the Sarathy2012 mechanism predicts autoignition of n-butanol, sec-butanol and tert-butanol satisfactorily but shows overprediction for conditions of $\phi=0.25$ and 20 bar.

Likewise, further studies on the predictability of different mechanisms including Sarathy2012 and Saggese2020 for the experiments carried out in this work in the HPST were performed. Figures 3 and 4 depict the comparison between the measured and simulated IDTs of propanol and butanol isomers whereas the simulated ones were based on the best mechanism for each case, respectively.

A

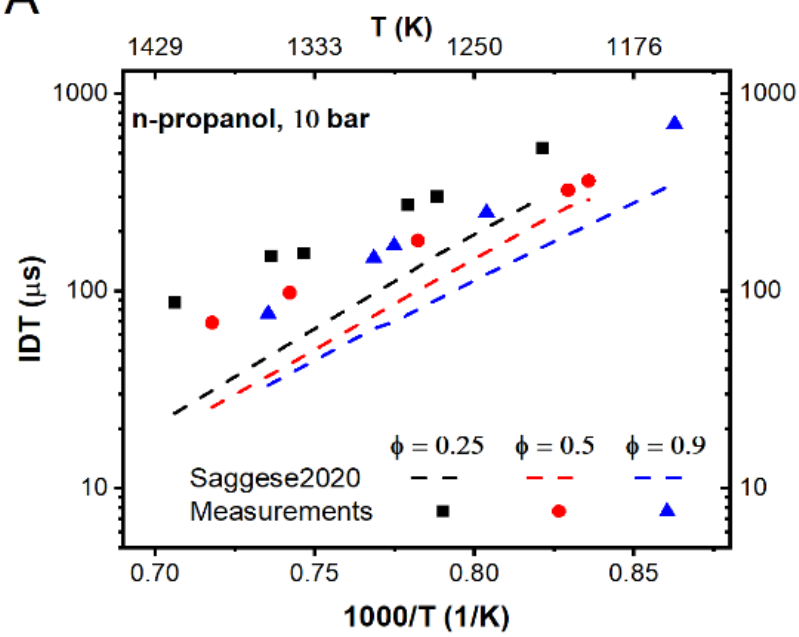

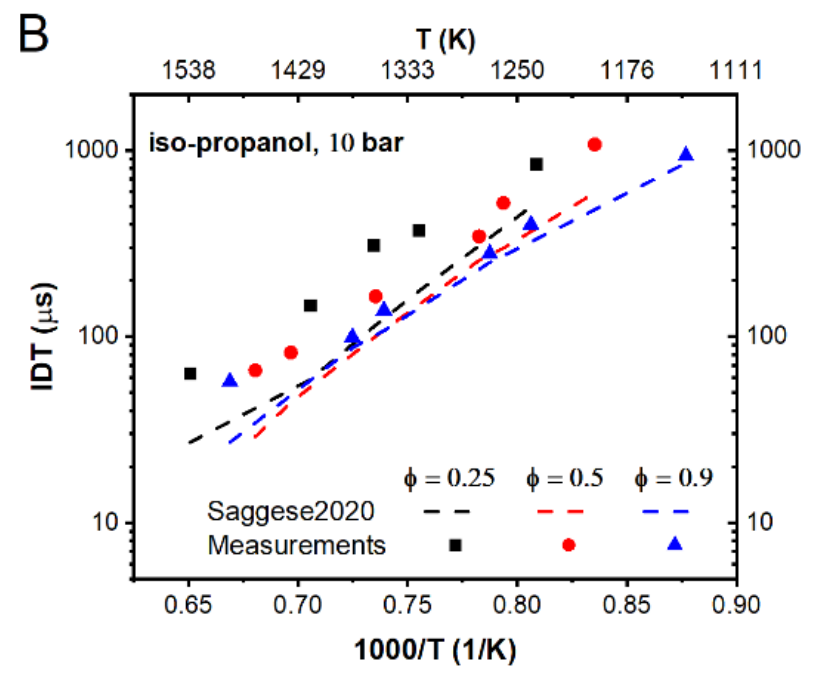

Figure 3. IDTs of (A) n-propanol, and (B) iso-propanol measured in the HPST at 10 bar and $\phi=0.25,0.5$, and 0.9.

For the propanol isomers, although the Saggese2020 mechanism underpredicts the reactivity, shows a good fit and captures the experimental trends with the same slope indicating the activation energy. It was not possible to simulate the IDTs of propanol isomers with the Sarathy2012 since it does not contain propanol species. For the butanol isomers, the Sarathy2012 mechanism shows better predictability in comparison to the Saggese2020, unless for the n-butanol that slight underprediction was found based on both mechanisms.

\subsection{Mechanism Development}

To have a comprehensive chemical reaction mechanism for all the propanol and butanol isomers, the Saggese 2020 and Sarathy 2012 mechanisms showed the best fit at both low and high temperatures in the prediction of the IDTs of the propanol and butanol isomers, respectively, were merged. The new mechanism was called the $\mathrm{C} 4$ mechanism consisting of 686 species and 3593 reactions which can be used for the numerical simulation of alcohols from C1 to C4 and their blends. Since, for most cases, the Sarathy 2012 mechanism shows very good prediction with the experiments, for those reactions which are identical in the Saggese2020 and Sarathy2012 mechanisms, the reactions, and the corresponding thermochemical and transport properties from Sarathy2012 were kept unchanged.

The Sarathy2012 mechanism was proposed by Sarathy and co-workers [27] to model the kinetic combustion of butanol isomers and validated against numerous experiments from 1 to $40 \mathrm{~atm}$ and low to high temperatures. This mechanism is comprised of 426 species and 2335 reactions.

The Saggese2020 mechanism includes 371 species and 2318 reactions, it is an improved revision of Sarathy2014 mechanism [47] developed by Saggese and co-workers for autoignition of n-propanol, iso-propanol, n-butanol, and iso-butanol, and has been 
validated against autoignition data from the literature [48]. In this mechanism, the reaction rate constants for $\mathrm{H}$-atom abstraction by $\mathrm{OH}$ and $\mathrm{HO}_{2}$, reactions involved in the lowtemperature oxidation, and the corresponding thermochemical properties were updated to simulate the autoignition of aforementioned alcohols at the stoichiometric ratio in low and high temperatures combustion.

A

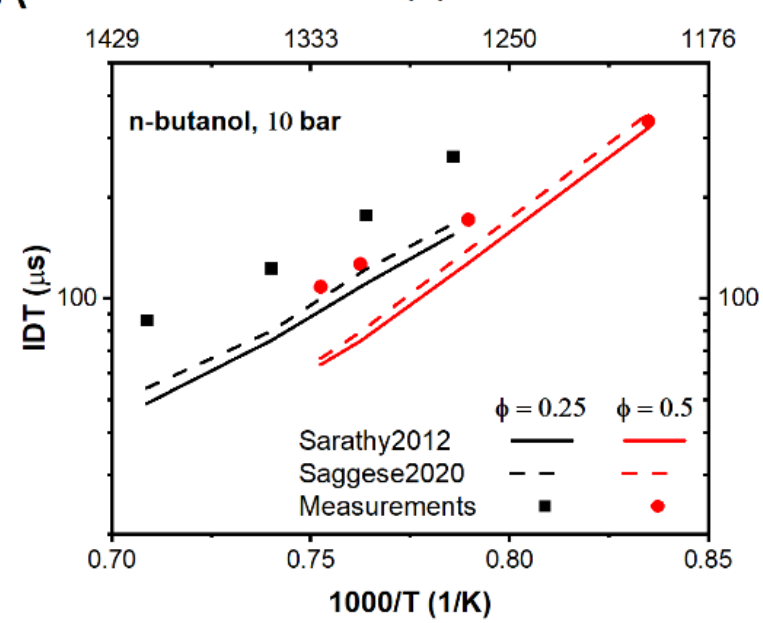

C

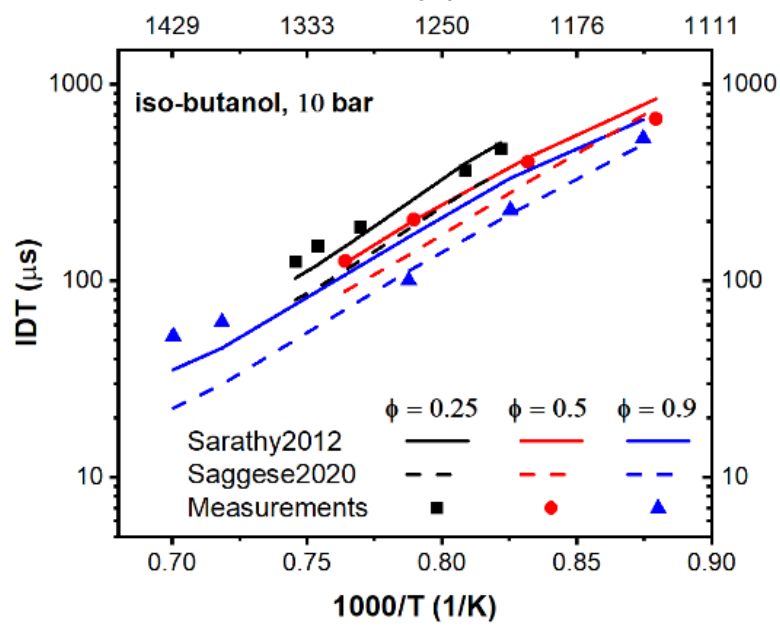

B
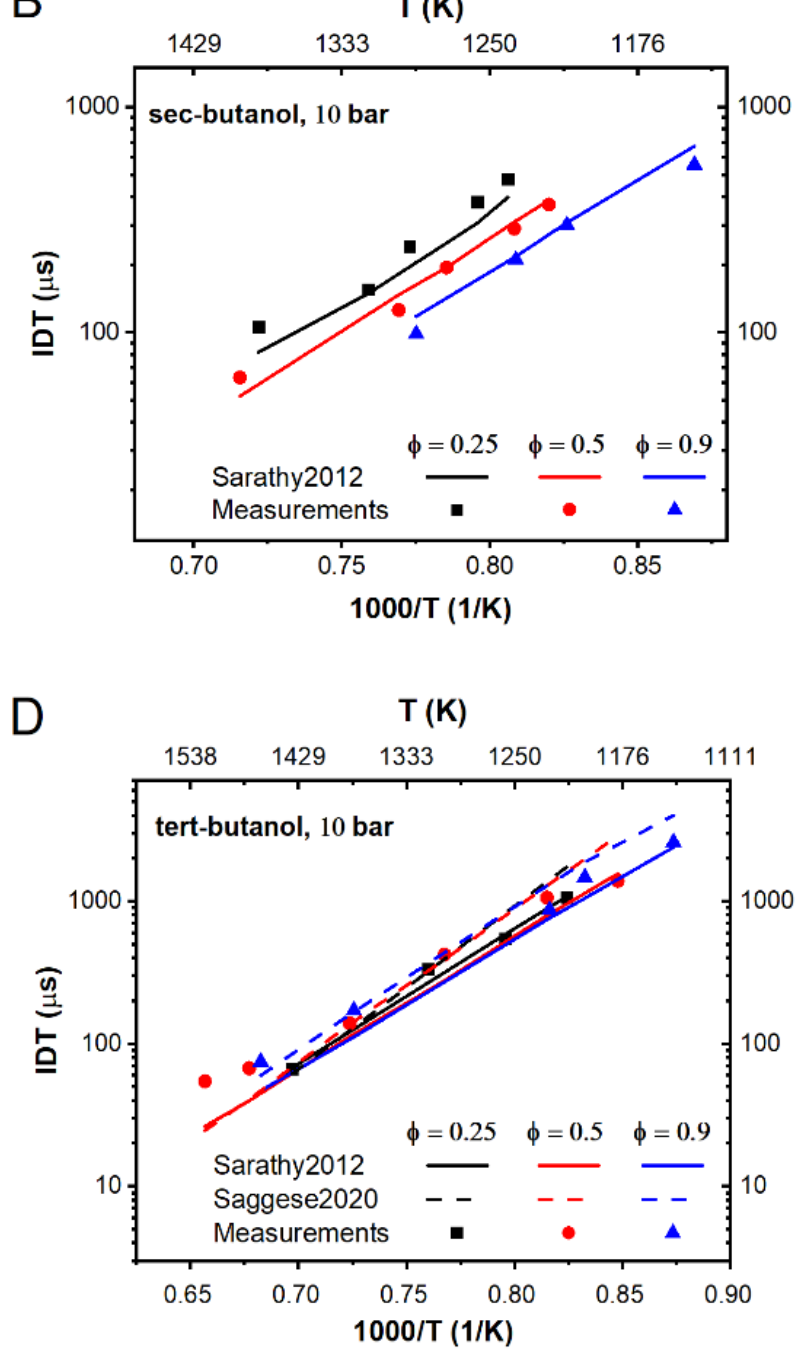

Figure 4. IDTs of (A) n-butanol, (B) sec-butanol, (C) iso-butanol, and (D) tert-butanol measured in the HPST at 10 bar and $\phi=0.25,0.5$, and 0.9 .

The evaluation of the $\mathrm{C} 4$ mechanism first was carried out by modeling the experiments data at low temperature measured in the RCM in our group by Wang $[39,41]$ and Laguna [40]. The comparison between the measured IDTs and the numerical model prediction based on the first version of C4 mechanism containing 3593 reactions is depicted in the Figure S2 in the Supplementary Material. Although our model's prediction improved significantly for the IDTs of the propanol isomers, it overpredicted the IDTs for butanol isomers (except n-butanol), especially at $\phi=0.25$ and 0.5 , which implies that adding the nonidentical reactions from Saggese2020 to the Sarathy2012 had an unfavorable impact on the predictability of the new mechanism. To address this problem, the sensitivity analysis for each fuel at different temperatures from 800 to $950 \mathrm{~K}$, pressures of 20 and $40 \mathrm{bar}$ and $\phi=0.25,0.5$, and 0.9 were performed. The next step was to search for the reactions with a positive sensitivity coefficient implying that the reactions which hinder the ignition event for butanol isomers, and with zero or negligible sensitivity coefficient for propanol isomers. 
Excluding the reactions, those have no impact on the reactivity of propanol but decrease the reactivity of the butanol, improved the performance of the mechanism considerably and the number of reactions in the newly emerged mechanism was reduced to 3402 .

Then the further evaluation of the $\mathrm{C} 4$ mechanism was made to investigate the performance of the mechanism at high temperature for the experiments performed in the HPST. The model was able to predict the IDTs of fuels precisely for equivalence ratios of 0.5 and 0.9 , but considerable discrepancies were observed for the IDT calculations at the equivalence ratio of 0.25 . Since the reactions of those that have the highest impact on the IDT calculation are principally different at high temperatures from those at low temperatures, more detailed sensitivity analysis at high temperatures were required. Figure 5 summarizes the 10 most important elementary reactions on the reactivity of each fuel at 10 bar, $\phi=0.25$, and temperatures at which the model showed the highest discrepancies indicated in the figure.

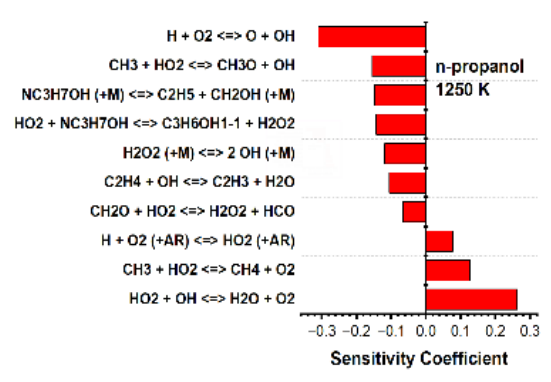

(a)

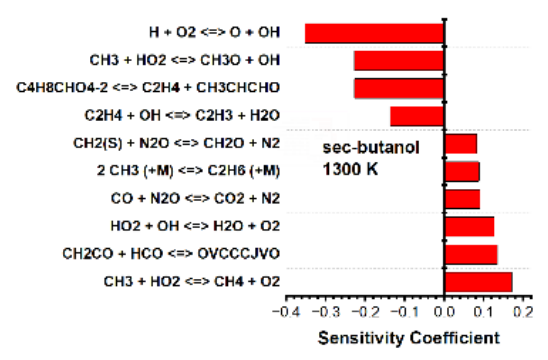

(d)

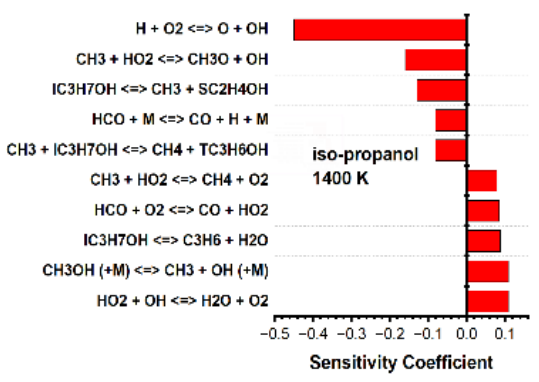

(b)

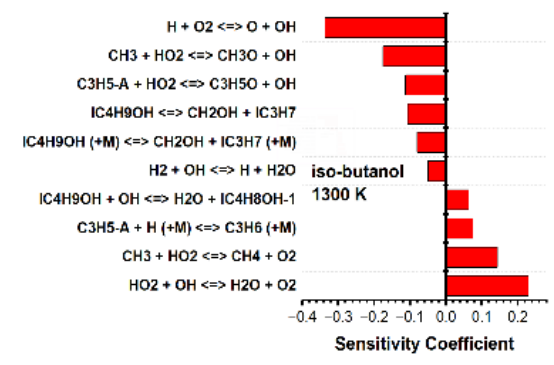

(e)

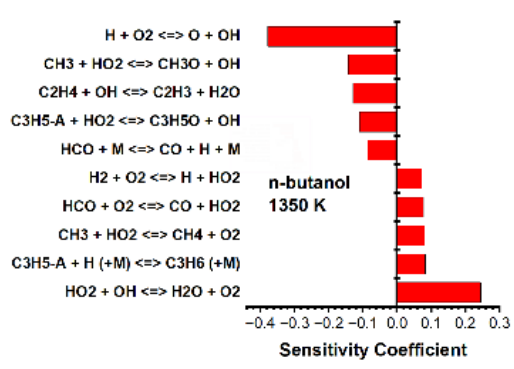

(c)

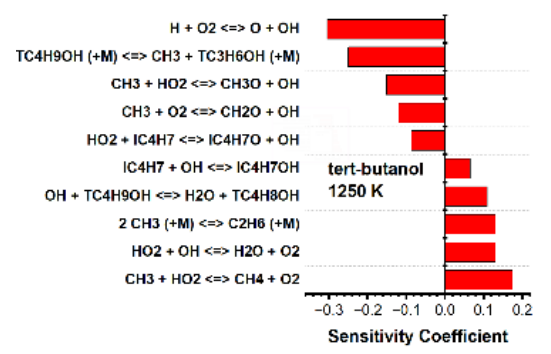

(f)

Figure 5. Sensitivity coefficients of the IDT at 10 bar and $\phi=0.25$ based on the C4 mechanism with 3402 reactions for (a) n-propanol at $1250 \mathrm{~K}$, (b) iso-propanol at $1400 \mathrm{~K}$, (c) n-butanol at $1350 \mathrm{~K}$, (d) sec-butanol at $1300 \mathrm{~K}$, (e) iso-butanol at $1300 \mathrm{~K}$, (f) tert-butanol at $1250 \mathrm{~K}$.

Since the calculated IDTs at high temperature based on the C4 mechanism, as illustrated in the Figure S1 in the Supplementary Material, were shorter than the experiments at $\phi=0.25$, the most sensitive elementary reactions with the negative sensitivity coefficient were noticed. Only four reactions have a high impact on the reactivity of the fuels at high temperatures but no impact at low temperature namely, $\mathrm{IC}_{4} \mathrm{H}_{9} \mathrm{OH} \Leftrightarrow=>\mathrm{CH}_{2} \mathrm{OH}+$ $\mathrm{IC}_{3} \mathrm{H}_{7}, \mathrm{IC}_{3} \mathrm{H}_{7} \mathrm{OH}<=>\mathrm{CH}_{3}+\mathrm{SC}_{2} \mathrm{H}_{4} \mathrm{OH}, \mathrm{NC}_{3} \mathrm{H}_{7} \mathrm{OH}(+\mathrm{M})<=>\mathrm{C}_{2} \mathrm{H}_{5}+\mathrm{CH}_{2} \mathrm{OH}(+\mathrm{M})$, and $\mathrm{C}_{4} \mathrm{H}_{8} \mathrm{CHO}_{4}-2 \Leftrightarrow=\mathrm{C}_{2} \mathrm{H}_{4}+\mathrm{CH}_{3} \mathrm{CHCHO}$ were identified. Since these reactions play an important role at temperatures higher than $1200 \mathrm{~K}$ and considering the uncertainty of the reaction rate constants corresponding to each reaction, the pre-exponential factor of each reaction rate constant was reduced by $30 \%$ to improve the performance of the model in predicting the IDTs at $\phi=0.25$.

Furthermore, among the rest of the crucial elementary reactions, the substitution of the reaction rate constants of two reactions, namely, $\mathrm{C}_{2} \mathrm{H}_{4}+\mathrm{OH} \Leftrightarrow=>\mathrm{C}_{2} \mathrm{H}_{3}+\mathrm{H}_{2} \mathrm{O}$ and $\mathrm{C}_{3} \mathrm{H}_{5}-$ $\mathrm{A}+\mathrm{HO}_{2} \Leftrightarrow=\mathrm{C}_{3} \mathrm{H}_{5} \mathrm{O}+\mathrm{OH}$ improved the performance of the mechanism substantially. It is important to note, that substituting the reaction rate constants of the elementary reactions showing the negative sensitivity coefficients with lower rate constants at high 
temperatures can enhance the calculated IDT; therefore, its influence at low temperatures must be considered as well.

The reaction rate constants of the $\mathrm{C}_{2} \mathrm{H}_{4}+\mathrm{OH} \Leftrightarrow=>\mathrm{C}_{2} \mathrm{H}_{3}+\mathrm{H}_{2} \mathrm{O}$ reported in Sarathy2012 mechanism are acquired from CurranPentane mechanism [49]. Since this reaction plays an important role at low temperature as well as high temperature, the predictability of the mechanism at low temperature must be kept and only at high temperature should be decreased. Figure 6 shows the comparison between the rate coefficients of $\mathrm{C}_{2} \mathrm{H}_{4}+\mathrm{OH}$ $<=>\mathrm{C}_{2} \mathrm{H}_{3}+\mathrm{H}_{2} \mathrm{O}$ reaction based on two different mechanisms in terms of temperature from 830 to $1795 \mathrm{~K}$. The rate coefficient based on the Master Chemical Mechanism (MCM v3.3.1) [50] is lower than the CurranPentane at high temperatures, while the differences between these two different reaction rate expressions reduce at low temperature. The rate expression of the reaction of ethylene and hydroxyl radicals is obtained by Senosiain et al. [51] employing quantum chemistry calculations.

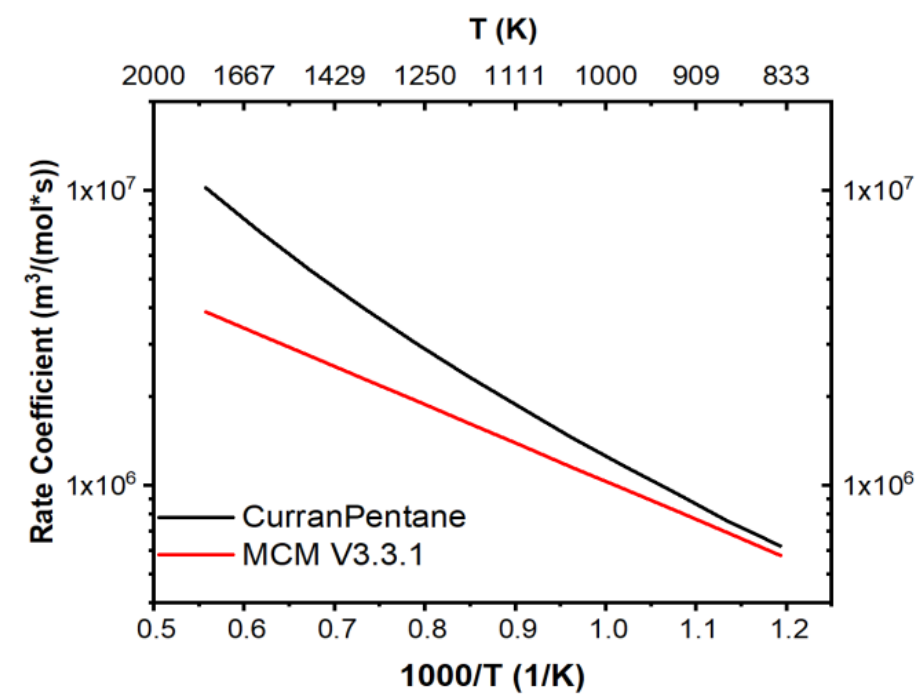

Figure 6. Rate coefficient of $\mathrm{C}_{2} \mathrm{H}_{4}+\mathrm{OH}<=>\mathrm{C}_{2} \mathrm{H}_{3}+\mathrm{H}_{2} \mathrm{O}$ reaction based on the CurranPentane and MCM v3.3.1 mechanisms.

Since the sensitivity coefficients corresponding to $\mathrm{C}_{3} \mathrm{H}_{5}-\mathrm{A}+\mathrm{HO}_{2}<=>\mathrm{C}_{3} \mathrm{H}_{5} \mathrm{O}+\mathrm{OH}$ reaction for the investigated fuels are negligible at a low temperature, modification of the reaction rate does not disturb the predictability of the mechanism at low temperature. The reaction rate adopted in the Sarathy 2012 mechanism is reported in a mechanism from Dooley and co-workers [52]. Substitution of the given rate coefficients with one adopted in the CurranPentane mechanism improved the model in the prediction of IDTs at a high temperature significantly. This reaction is provided in the CurranPentane mechanism as a pressure-dependent reaction, while five different rate expressions were specified at five specific pressures from 0.01 to $100 \mathrm{~atm}$. Figure 7 shows the comparison between the rate coefficients of $\mathrm{C}_{3} \mathrm{H}_{5}-\mathrm{A}+\mathrm{HO}_{2}<=>\mathrm{C}_{3} \mathrm{H}_{5} \mathrm{O}+\mathrm{OH}$ reaction based on two different mechanisms in terms of temperature from 830 to $1795 \mathrm{~K}$ at 10 bar. As discussed before, the lower rate coefficient of this reaction from the CurranPentane mechanism does not have an influence on the predictability of the mechanism at low temperature.

Finally, the newly developed C4 mechanism comprised of 595 species and 3398 reactions was achieved. To improve the ability of the model to simulate the NOx emissions producing from the autoignition of alcohols at lean condition, the hydrocarbon-nitrogen, nitro and nitroso hydrocarbon, and amino hydrocarbon sub-mechanism and the corresponding thermodynamic properties from the nitrogen mechanism proposed by Glarborg and co-workers [53] were added to the mechanism that led to a new comprehensive mechanism consisting of 684 species and 3898 reactions. 


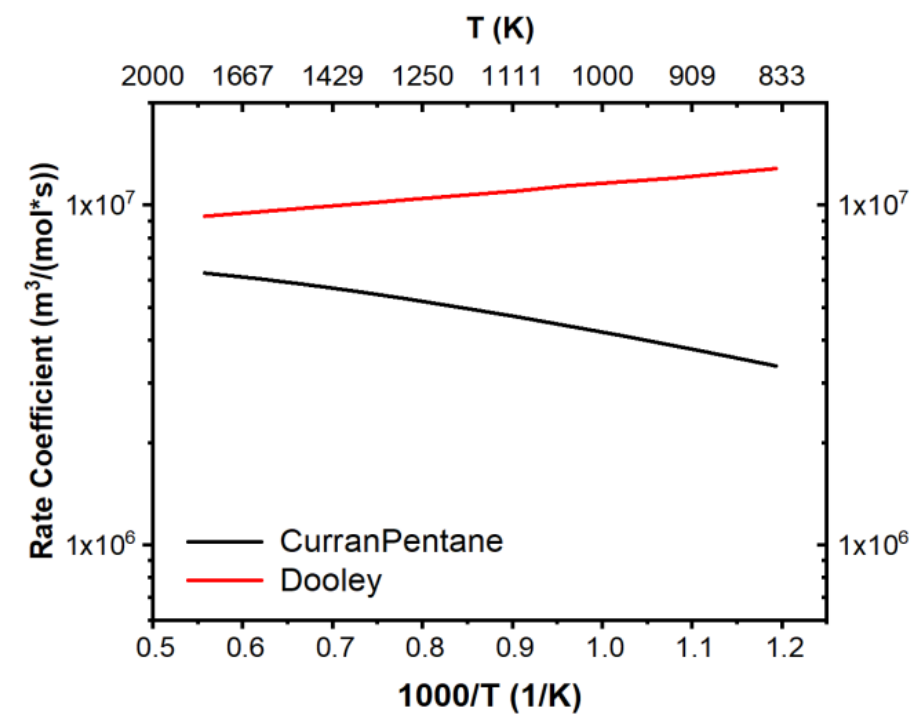

Figure 7. Rate coefficient of $\mathrm{C}_{3} \mathrm{H}_{5}-\mathrm{A}+\mathrm{HO}_{2}<=>\mathrm{C}_{3} \mathrm{H}_{5} \mathrm{O}+\mathrm{OH}$ reaction based on the CurranPentane and Dooley mechanisms at 10 bar.

\subsection{The New Mechanism Validation}

The newly developed C4 mechanism was validated first against the IDTs measured in the HPST (this work) and RCM (previous works in our group). Figures 8 and 9 depict the comparison between simulations and experimental results measured in HPST at 10 bar, $\phi=0.25,0.5$, and 0.9 for propanol and butanol isomers, respectively. The C4 mechanism predicts the experimental trends precisely for each fuel at all the equivalence ratios, even at a very lean condition with a very small amount of fuel.

A

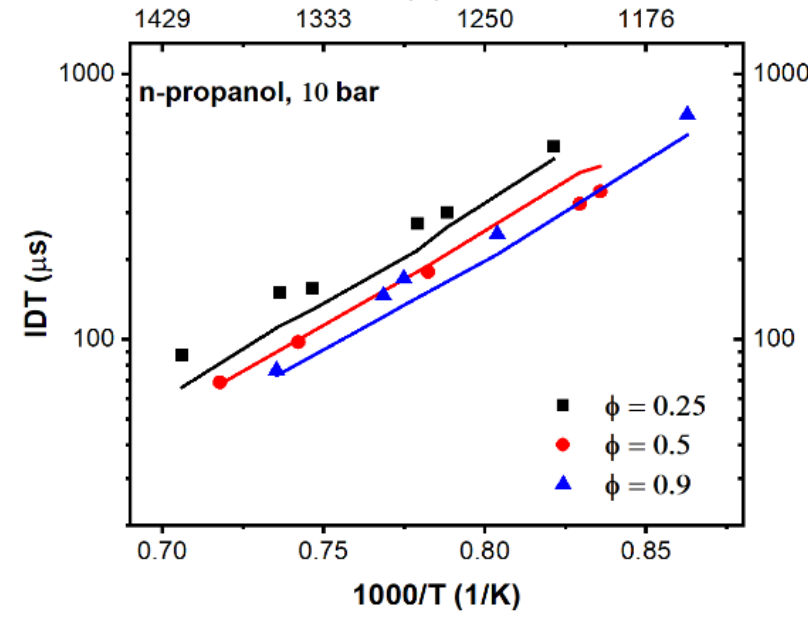

B

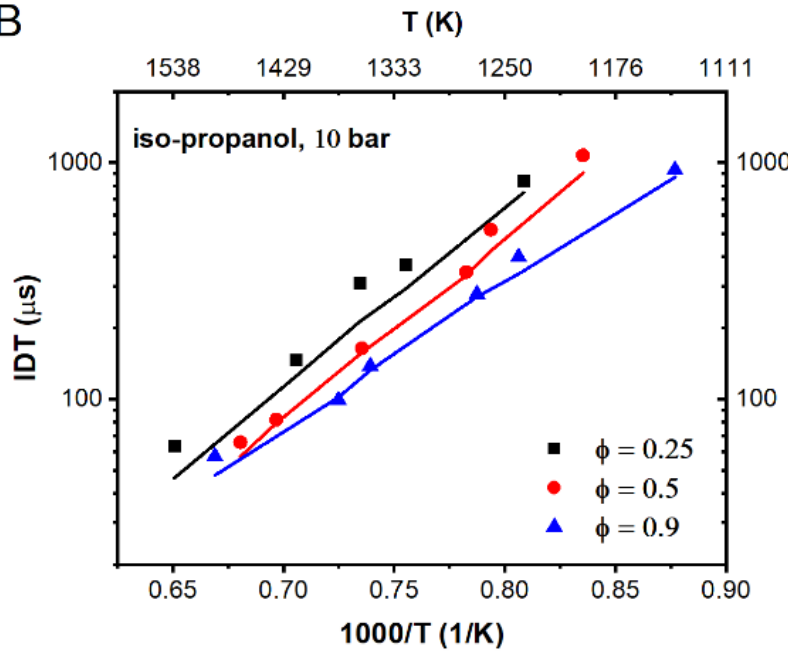

Figure 8. IDTs of (A) n-propanol, and (B) iso-propanol measured in the HPST at 10 bar and $\phi=0.25,0.5$ and 0.9. (Symbols: experimental points; Lines: model predictions).

Figures 10 and 11 represent the IDTs from simulation and experiments in RCM at 20 and 40 bar, $\phi=0.25,0.5$, and 0.9 for propanol and butanol isomers, respectively. Further validation of the $\mathrm{C} 4$ mechanism for the low-temperature combustion, proved that this $\mathrm{C} 4$ mechanism can predict the IDTs acceptably at both 20 and 40 bar with a small discrepancy for the sec-butanol and tert-butanol. Nevertheless, the prediction of the IDTs of sec-butanol and tert-butanol by this $\mathrm{C} 4$ mechanism was closer to the experiments compared to the Sarathy2012 mechanism reported by Wang [39,41] and Laguna [40]. 
A

\section{$\mathbf{T}(\mathbf{K})$}

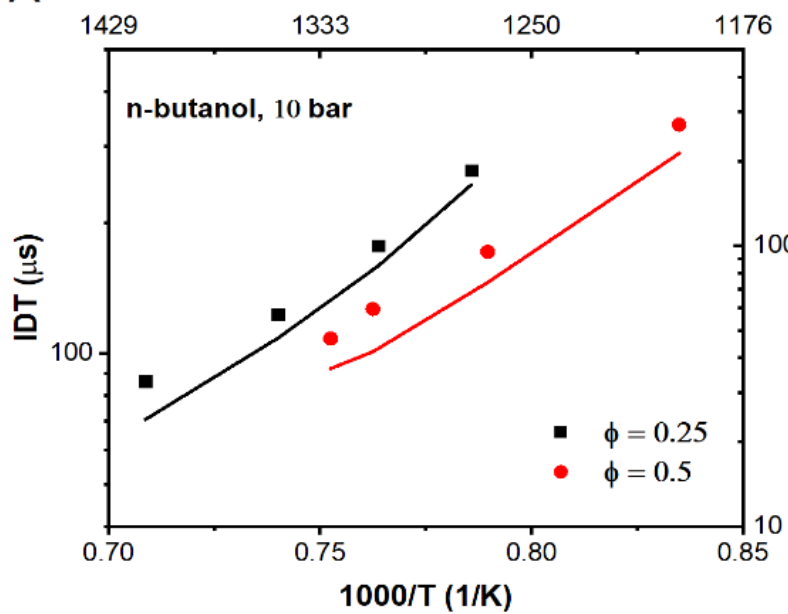

C

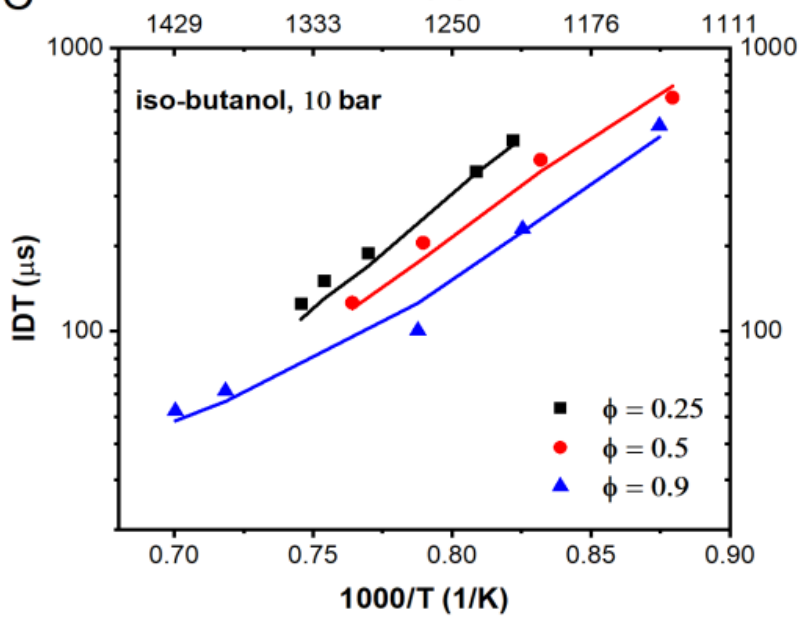

B

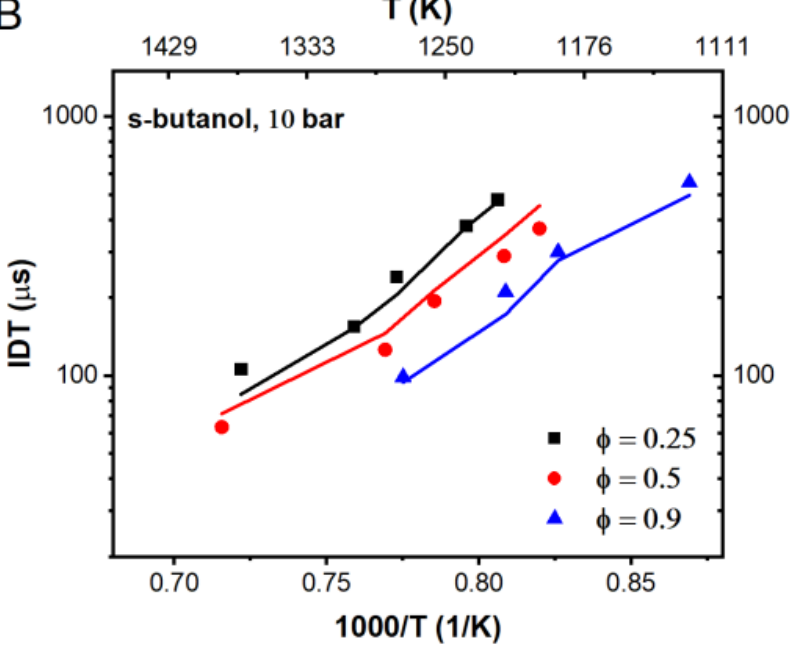

$\mathrm{D}$

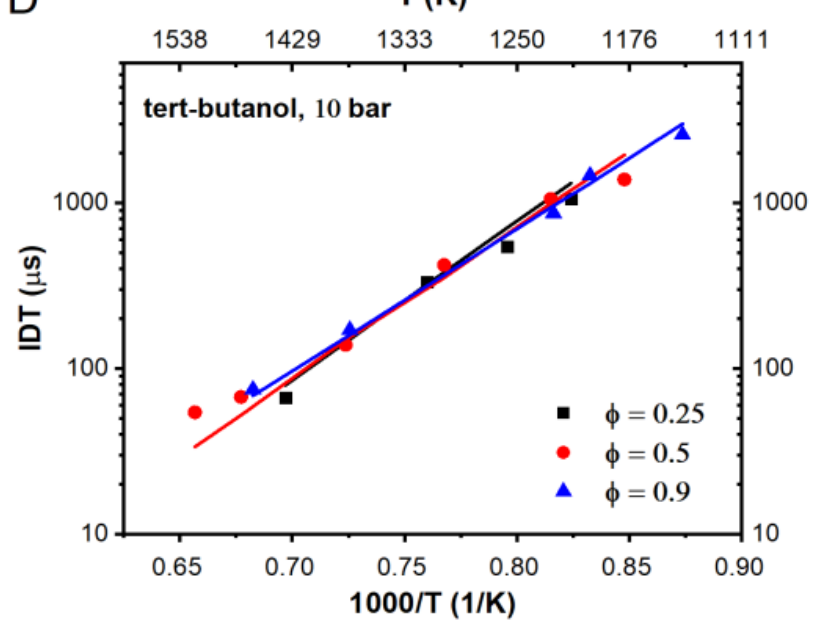

Figure 9. IDTs of (A) n-butanol, (B) sec-butanol, (C) iso-butanol, and (D) tert-butanol measured in the HPST at 10 bar and $\phi=0.25,0.5$, and 0.9. (Symbols: experimental points; Lines: model predictions).

A

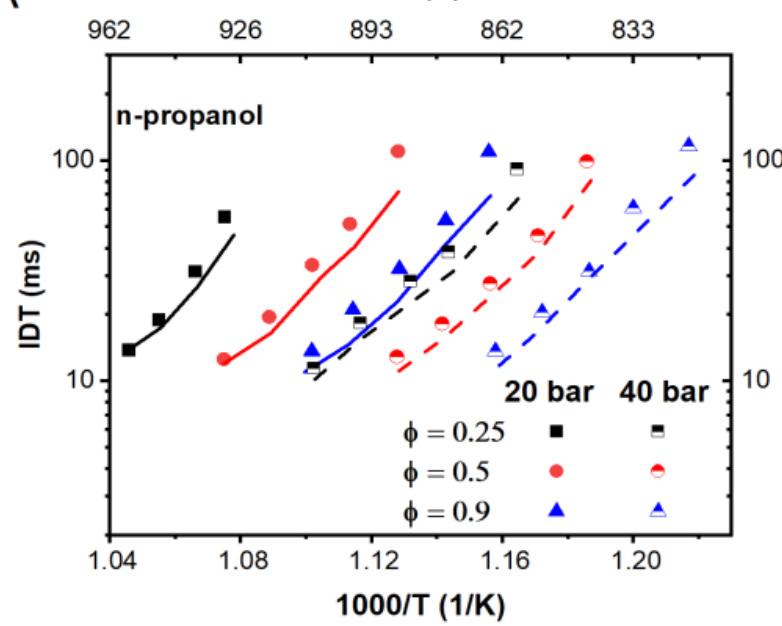

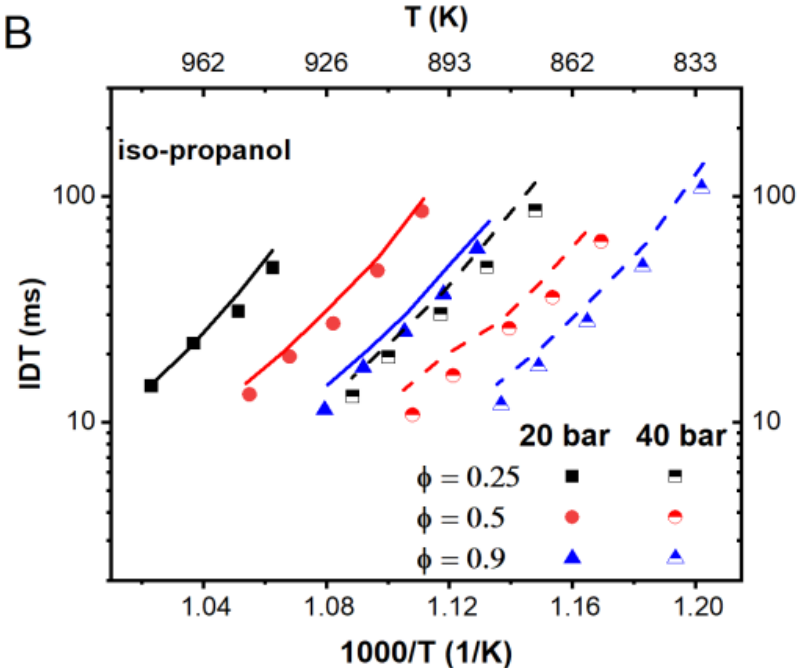

Figure 10. IDTs of (A) n-propanol and (B) iso-propanol measured in the RCM [39-41] at 20 and 40 bar and $\phi=0.25,0.5$, and 0.9. (Symbols: experimental points; Lines: model predictions). 
A
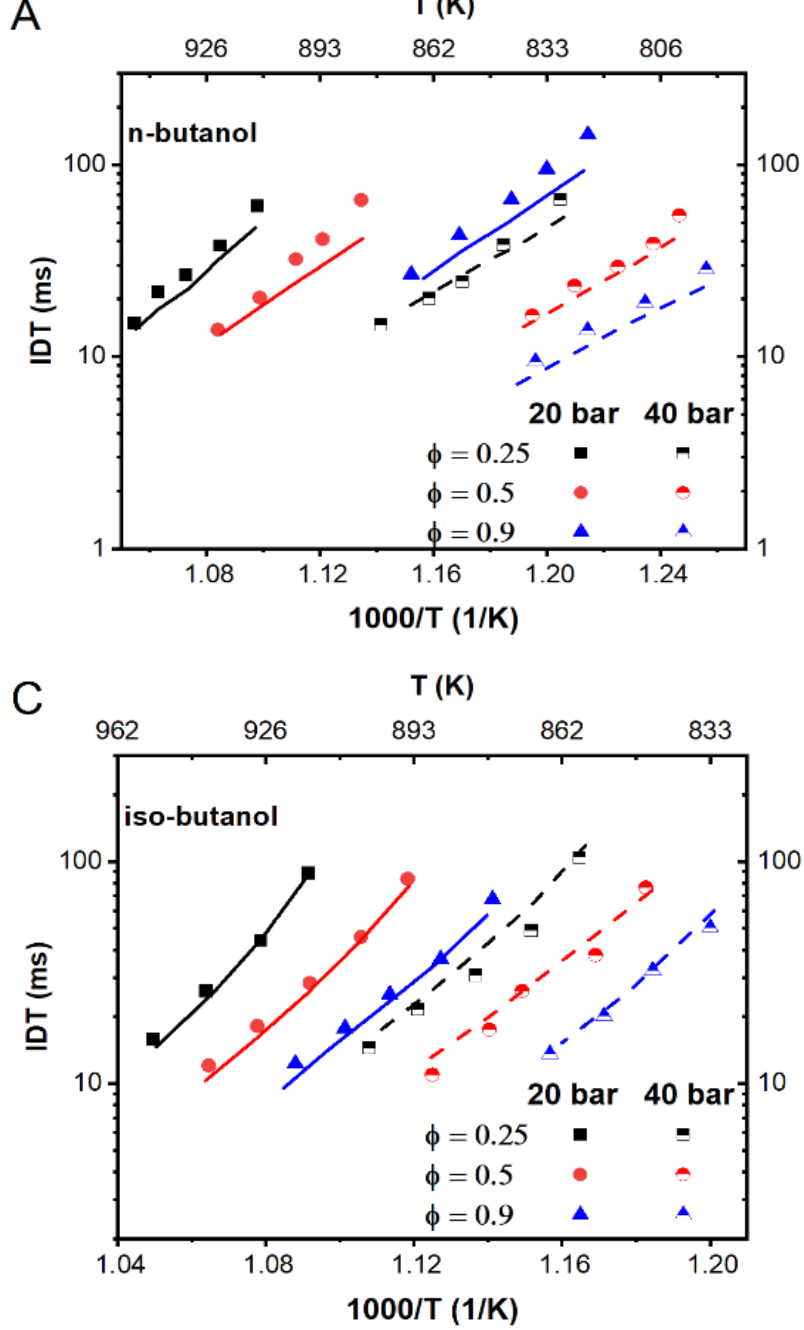

B

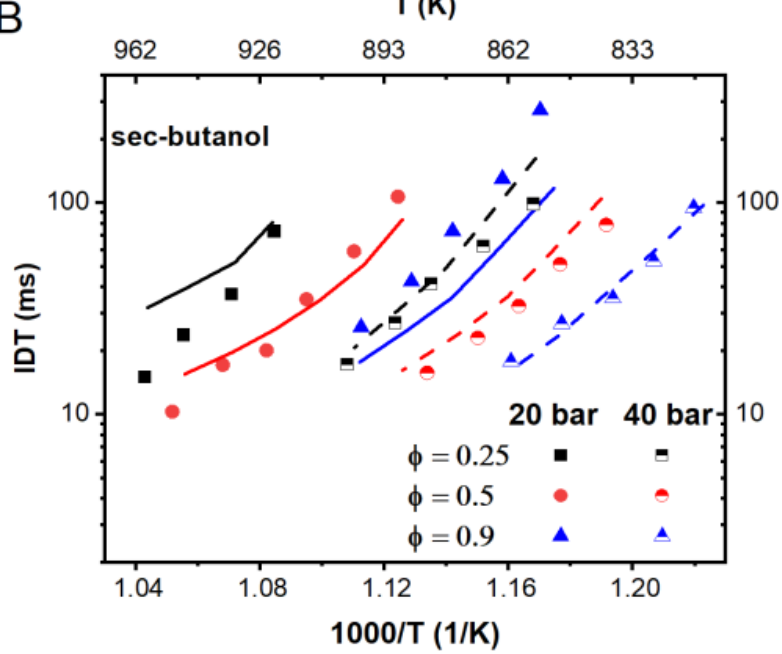

$\mathrm{D}$

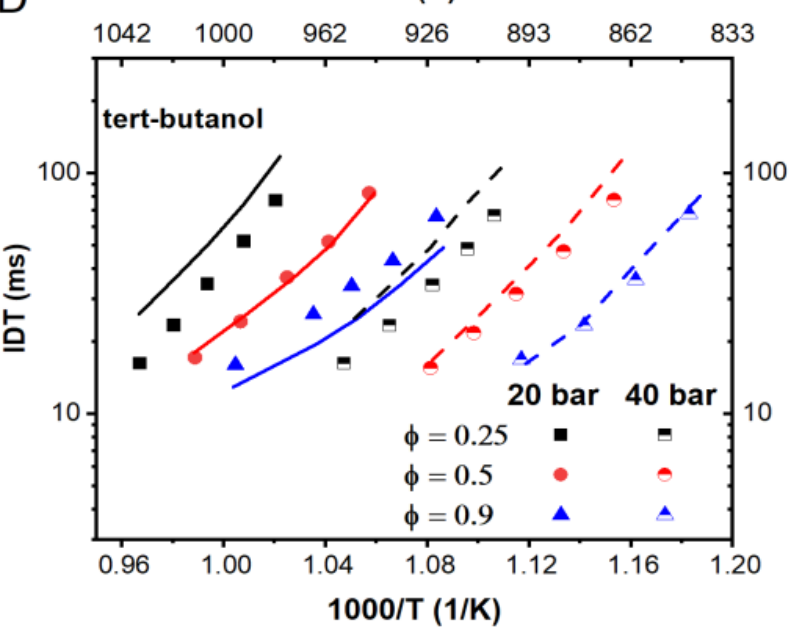

Figure 11. IDTs of (A) n-butanol, (B) sec-butanol, (C) iso-butanol, and (D) tert-butanol measured in the RCM [39-41] at 20 and 40 bar and $\phi=0.25,0.5$ and 0.9. (Symbols: experimental points; Lines: model predictions).

Beside ignition delay, laminar burning velocity (LBV) is another key combustion property. To validate the $\mathrm{C} 4$ mechanism for the use in simulations of laminar burning velocity, experimental data of laminar burning velocity were taken from Veloo et al. [34] for C4-alcohols, and Veloo et al. [35] for C3-alcohols. These data and the simulation results from Sarathy2014 [47], Saggese2020 [36] and the newly developed C4 mechanism are compared in Figure 12.

It can be seen, that for n-propanol all mechanisms show higher reactivity than the experimental result. In lean mixtures, Sarathy2014 and the C4 mechanism show similar and good results with a discrepancy within $10 \%$. For rich mixtures with $\phi \geq 1.2$, this difference increases significantly. Saggese2020 predicts the highest LBVs compared to the other mechanisms.

Sarathy2014 and the newly developed C4 mechanism are in very good approximation for iso-propanol mixtures with $0.8<\phi \leq 1.2$ with a deviation of less than $5.6 \%$ (Sarathy2014), and $7.7 \%$ (this work), respectively. Both Sarathy 2014 and the new C4 mechanism show a slightly lower reactivity than the experimental results predict for conditions with $\phi \leq 0.8$. Saggese2020 overpredicts the reactivity of iso-propanol. For mixtures with $\phi>1$, the overprediction is more than $10 \%$.

The developed C4 mechanism has very good predictability for all butanol isomers in the range of $0.8 \leq \phi \leq 1.2$ with less than $10 \%$ deviation from the experimental results (except for iso-butanol at $\phi=0.9$ ). For sec-butanol and iso-butanol the reactivity is underestimated 
by $5-10 \%$ around stoichiometric mixtures. Compared to Saggese2020 and Sarathy 2014 the predictions of the newly developed C4 mechanism for tert-butanol are superior.
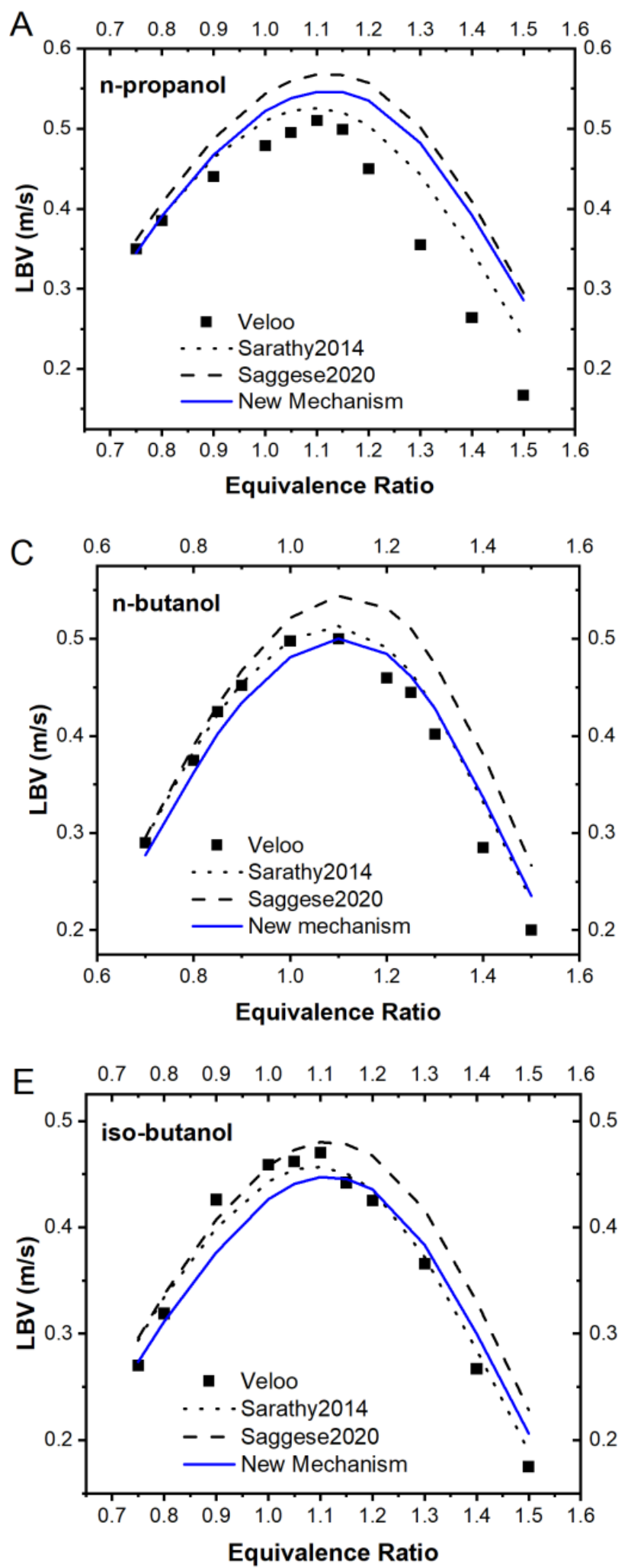
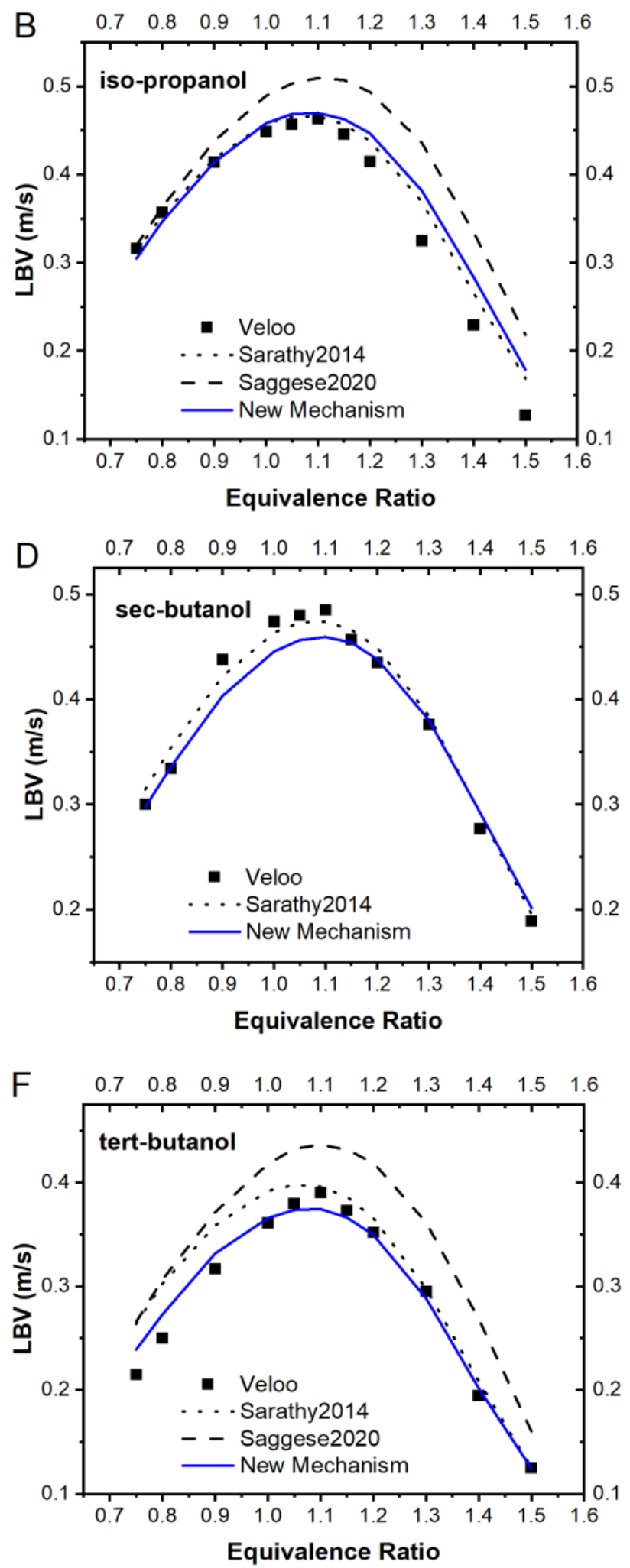

Figure 12. Laminar burning velocity of (A) n-propanol, (B) iso-propsanol, (C) n-butanol, (D) sec-butanol, (E) iso-butanol, and (F) tert-butanol at $343 \mathrm{~K}$ in air at $\mathrm{P}=1$ bar. Symbols represent experimental data from Veloo et al. [34]. 
For all six considered fuels, the newly developed C4 mechanism gives good predictions on the laminar burning velocity, especially for the lean cases, which are predominant for further investigations in this study.

\subsection{Modeling LPP for Aviation}

\subsubsection{Ignition Delay Time and Laminar Burning Velocity Prediction of the Model}

To evaluate the suitability of C3- and C4-alcohols as fuels for LPP combustion, their ignition delay time (IDT) and laminar burning velocity (LBV) are simulated with the C4 mechanism at engine-relevant conditions in comparison to the conventional commercial jet fuel Jet- $\mathrm{A}$ as a kerosene-type fuel. In addition, the species concentration of $\mathrm{CO}$, soot precursors, such as $\mathrm{C}_{2} \mathrm{H}_{2}$ and $\mathrm{C}_{4} \mathrm{H}_{2}$, and NOx emissions are shown.

The temperature in the mixing section prior to the LPP combustion chamber is calculated from a compressor with an overall pressure ratio $O P R=36$, a compressor efficiency $\eta_{\text {comp }}=0.9$ and the ratio of heat capacities $\kappa=1.4$. The outside, non-compressed temperature is defined as follow [54] at $T_{0}=288.15 \mathrm{~K}$ and $p_{0}=1 \mathrm{~atm}$.

$$
T_{\text {comp }, \text { outlet }}=T_{0} *\left(1+\left(O P R^{(\kappa-1) / \kappa}-1\right) / \eta_{\text {comp }}\right.
$$

The conditions for combustion are accordingly defined as $T_{\text {comp,outlet }}=860 \mathrm{~K}$ and $p_{\text {comp }, \text { outlet }}=36 \mathrm{~atm}$.

Figure 13 represents the model prediction for IDT and LBV of the non-diluted propanol and butanol isomer, and the Jet-A surrogate mixtures with air at $860 \mathrm{~K}, 36 \mathrm{~atm}$ and equivalence ratios of $0.25,0.75$, and 1.2. Each fuel shows greater reactivity at a higher equivalence ratio owing to the presence of more fuel in the mixture. The numerical simulation predicts the higher reactivity of n-butanol at both lean and rich fuel-air conditions in comparison to other species while the experimental results obtained in HPST and those from RCM [39-41] confirm this finding undoubtedly.

A

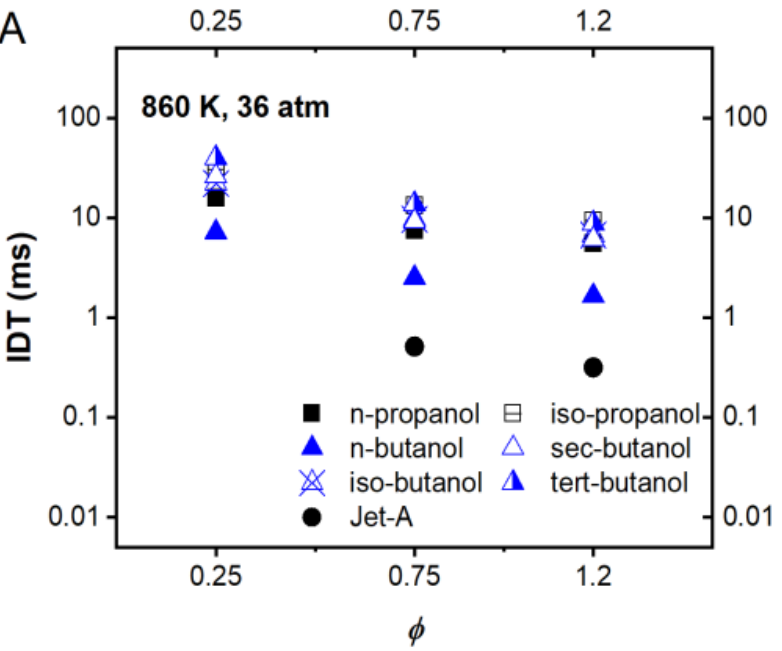

B

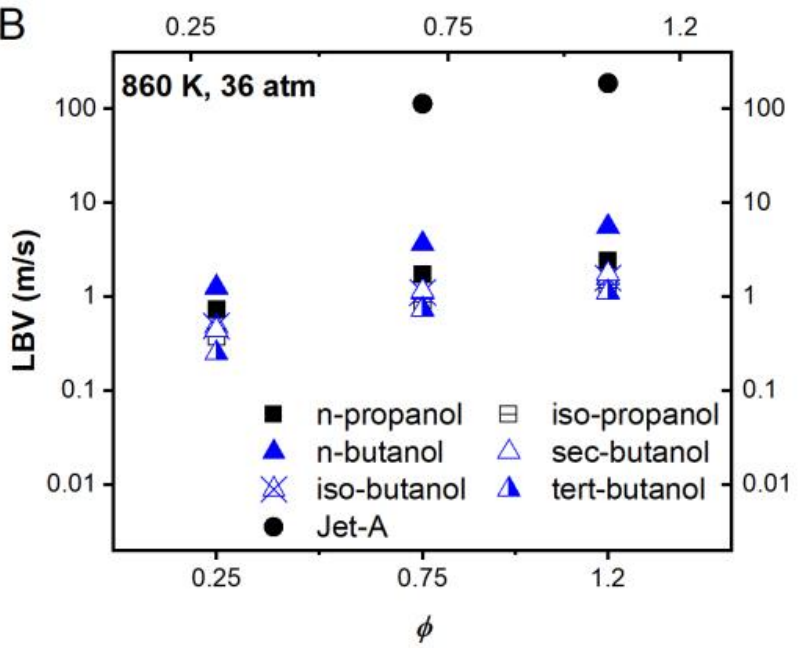

Figure 13. Model prediction for (A) IDT and (B) LBV of the propanol and butanol isomers, and the Jet-A surrogate at $860 \mathrm{~K}$, $36 \mathrm{~atm}$ and equivalence ratios of $0.25,0.75$, and 1.2 .

To compare each alcohol separately, the reactivity of the n-propanol is higher than the iso-propanol because of different decomposition mechanisms. Frassoldati and coworkers [28] demonstrated that the radical pathways forming a significant amount of propanal is the reason for the higher reactivity of n-propanol.

In addition, $\mathrm{n}$-butanol is the most reactive of the four butanol isomers. These isomers follow different chemical reaction pathways including molecular decomposition, initiation reactions to form alkyl radicals, and chain propagation reactions that cause different reactivity. On the other hand, there is a notable difference between the reactivity of 
four-carbon chain isomers, i.e., n-butanol and sec-butanol, while the reactivity of sec-, isoand tert-butanol are equivalent.

The so-called Aachen surrogate composed of 80\% n-decane and 20\% 1,2,4-trimethylbenzene by weight, were defined in our numerical studies to investigate the IDT and LBV of Jet-A based on the mechanism proposed by their group. Honnet et al. [55] proved that the Aachen surrogate accurately reproduces the ignition properties of kerosene. The Jet-A model did not reach a steady-state solution for equivalence ratios of $\phi \leq 0.5$. The model predicts the significantly highest LBVs and lowest IDTs for Jet-A. This underlines the problems of Jet-A as an LPP fuel as it has a high flashback tendency, which seems to be uncontrollable.

N-propanol and n-butanol show faster flame speeds compared to the other C3 and $\mathrm{C} 4$ alcohols, which was to be expected due to their long-chain nature. Tert-butanol has the lowest LBV, followed by iso-propanol, which is desirable for LPP combustion due to the lower flashback tendency. The overall order of flame speeds is reasonably showing the same trend as the reactivity shown by IDTs in Figure 13. As the adiabatic flame temperatures of the seven fuels have only minor differences of $2.5 \%$ and less, the difference in LBV is suggested to be predominantly caused by kinetics.

\subsubsection{Emission Prediction of the Model}

Although the e-fuels are carbon neutral, the emissions of $\mathrm{CO}, \mathrm{NOx}$ and particular matters have a strong impact on the environment. To analyze the impact of e-fuels on the environment by calculating their emissions contribution, the numerical simulation based on the $\mathrm{C} 4$ mechanism at the engine condition for two lean mixtures, i.e., $\phi=0.25$ and 0.75 were implemented and compared with the same condition at $\phi=1.2$. Figure 14 compares the final mole fraction of $\mathrm{CO}$ and $\mathrm{NOx}$ emissions at different equivalence ratios and the engine-related conditions for all fuels calculated by the chemical kinetic model during the ignition process. The model predicts that the final mole fractions of $\mathrm{CO}$ and $\mathrm{NOx}$ emissions after ignition are the highest at $\phi=1.2$ compared to the lean conditions. These values at $\phi=0.75$ are nearly close to those of at $\phi=1.2$, whereas the emissions at $\phi=1.2$ are of the order of 10 higher than the emissions at $\phi=0.75$. Additionally, the emissions at $\phi=0.75$ and 1.2 are almost 6 orders of magnitude higher than those at $\phi=0.25$ for NO, $\mathrm{NO}_{2}$, and $\mathrm{CO}$.

Further gas-phase kinetics modeling was performed to compare the formation of soot of targeted fuels at different $\phi$ for the engine-related conditions. In this respect, the kinetic modeling of the formation of acetylene $\left(\mathrm{C}_{2} \mathrm{H}_{2}\right)$ and diacetylene $\left(\mathrm{C}_{4} \mathrm{H}_{2}\right)$ was taken into account as the soot precursors [56,57]. Figure 15 compares the maximum mole fraction of soot precursors, including $\mathrm{C}_{2} \mathrm{H}_{2}$ and $\mathrm{C}_{4} \mathrm{H}_{2}$ at different equivalence ratios and the enginerelated conditions for all fuels calculated by the chemical kinetic model during the ignition process, illustrating the highest emissions at the fuel-rich condition and the lowest emission at ultra-lean condition.

The production and emission of $\mathrm{NO}, \mathrm{NO}_{2}, \mathrm{~N}_{2} \mathrm{O}$, and $\mathrm{CO}$ in terms of the length of a free flame can be seen in Figure 16. It is notable, that the flame fronts and main zone of reaction of each of the alcohols are in a similar position at $Z=0.01 \mathrm{~m}$. While at $\phi=0.75$ and $\phi=1.2$ the pollutant formation occurs over a short distance and thus in a short time, at $\phi=0.25$ the mole fractions of the pollutants under consideration stabilize after this point.

The model predictions of the leanest case at $\phi=0.25$ indicate the least $\mathrm{CO}$ emissions, as most of the $\mathrm{CO}$ can be further oxidized to $\mathrm{CO}_{2}$ in the zone behind the flame front. The $\mathrm{CO}$ mole fraction in the flame of $\mathrm{n}$-butanol is being oxidated after $Z=0.03 \mathrm{~m}$ and reaches a concentration below the emissions of $\phi=0.75$. As expected, the mole fraction of $\mathrm{CO}$ emission increases with an increase of equivalence ratio to around 4 to $7 \mathrm{~mol} \%$ at $\phi=0.75$, and 9 to $11 \mathrm{~mol} \%$ at $\phi=1.2$, respectively. 


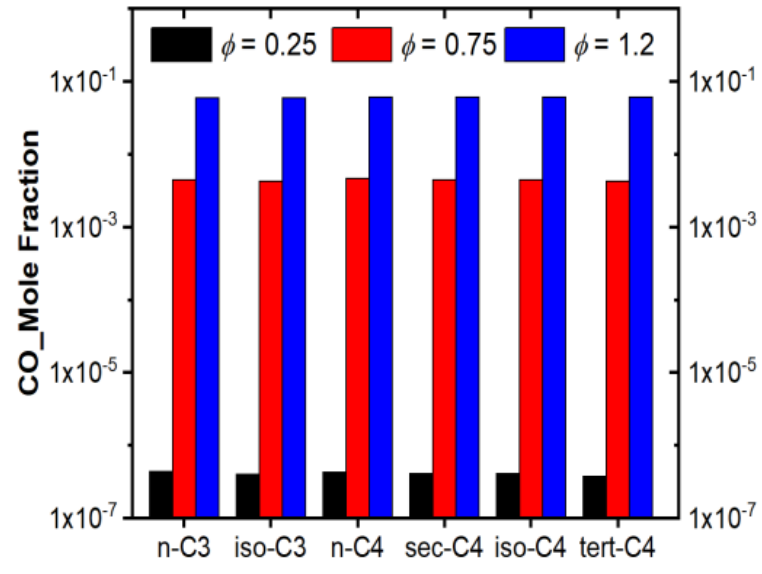

(a)

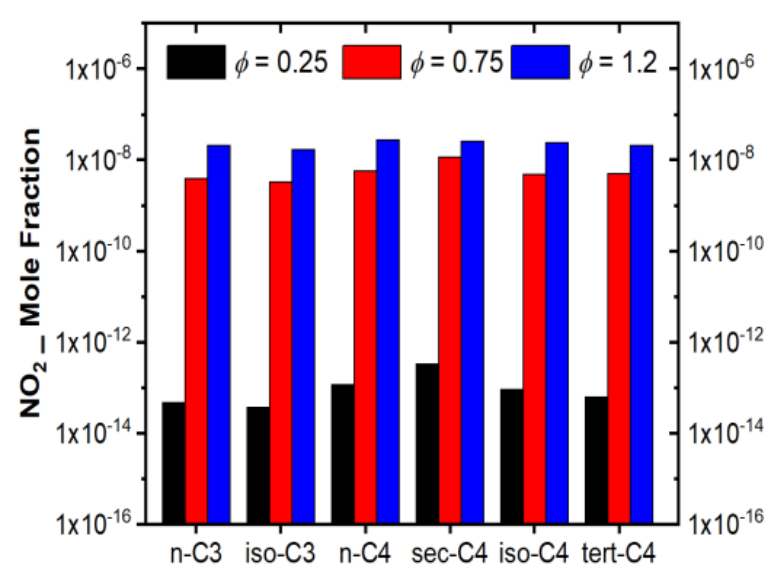

(c)

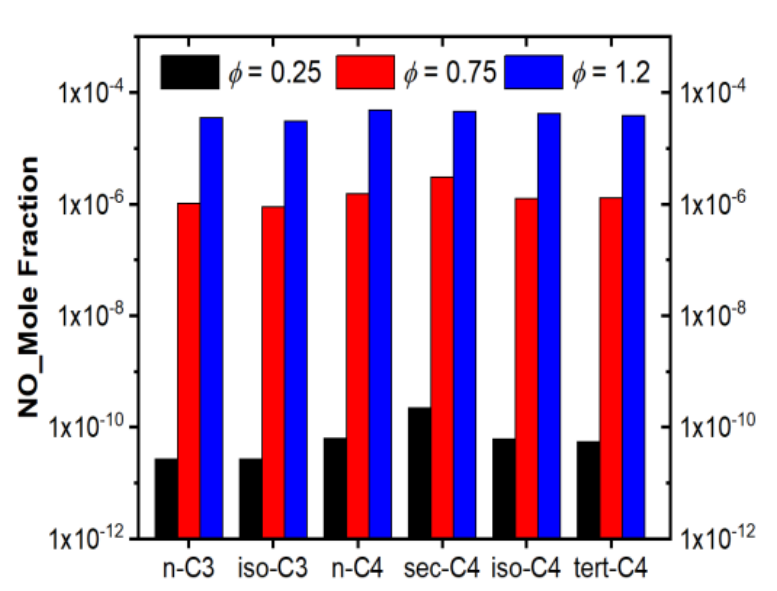

(b)

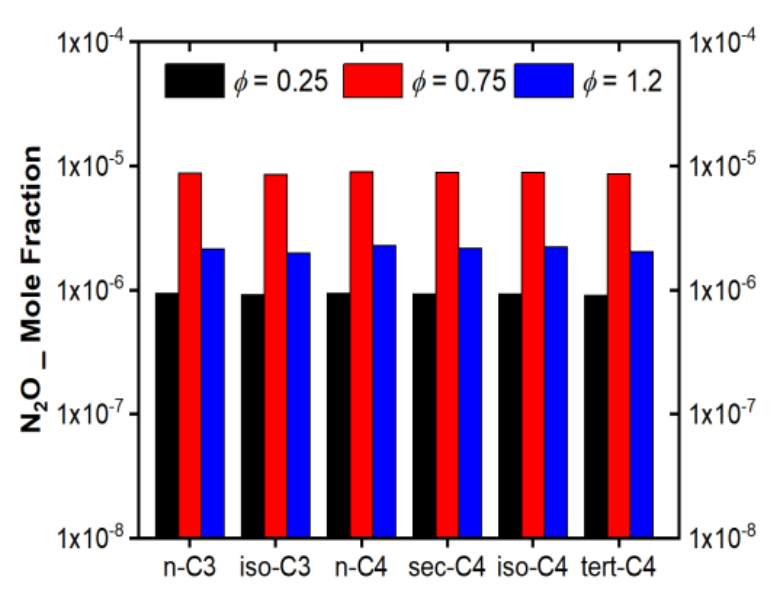

(d)

Figure 14. Model prediction for the final mole fraction of (a) $\mathrm{CO},(\mathbf{b}) \mathrm{NO},(\mathbf{c}) \mathrm{NO}_{2}$, and (d) $\mathrm{N}_{2} \mathrm{O}$ emissions from the oxidation of propanol and butanol isomers during the ignition process at $860 \mathrm{~K}$ and $36 \mathrm{~atm}$ for the unburned fuel/air-mixture.

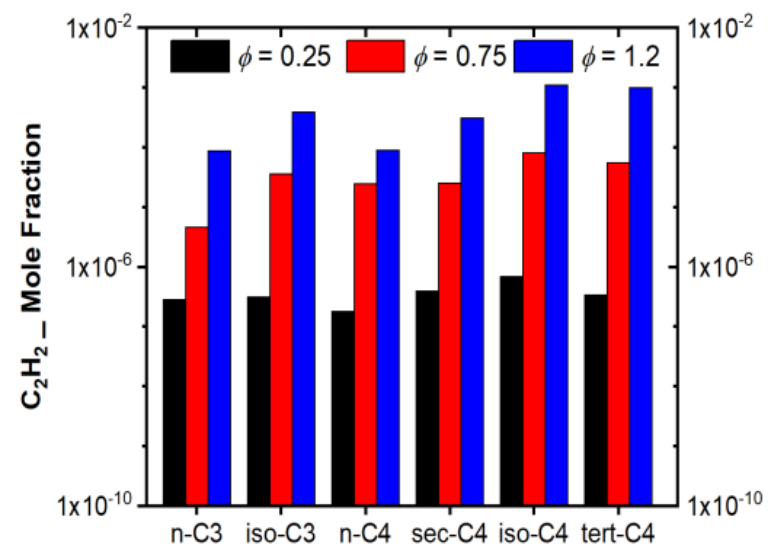

(a)

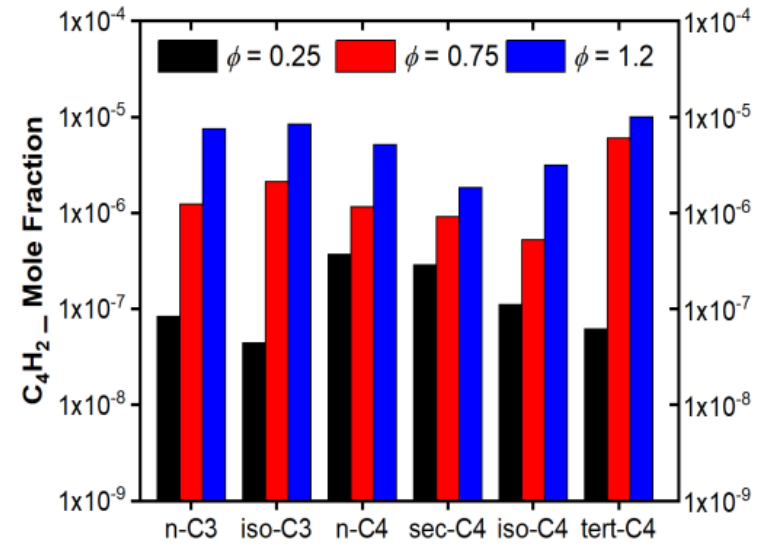

(b)

Figure 15. Model prediction for the peak value of (a) $\mathrm{C}_{2} \mathrm{H}_{2}$, and (b) $\mathrm{C}_{4} \mathrm{H}_{2}$ mole fraction from the oxidation of propanol and butanol isomers during the ignition process at $860 \mathrm{~K}$ and $36 \mathrm{~atm}$ for the unburned fuel/air-mixture. 


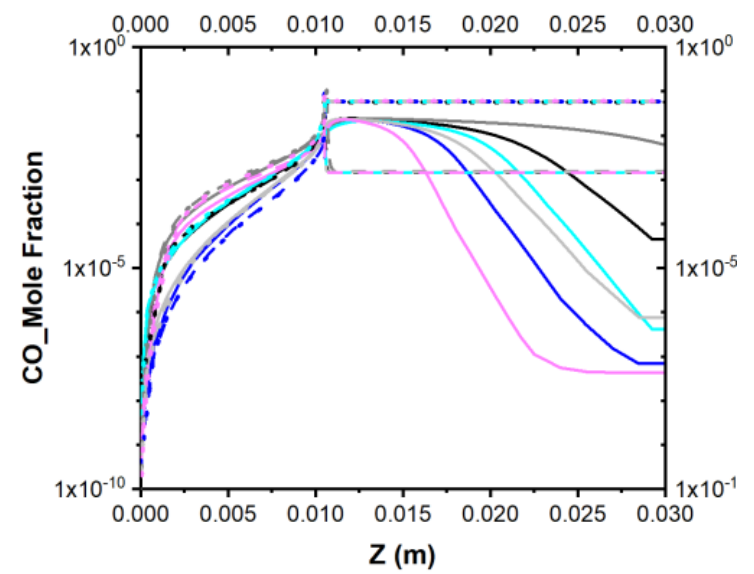

(a)

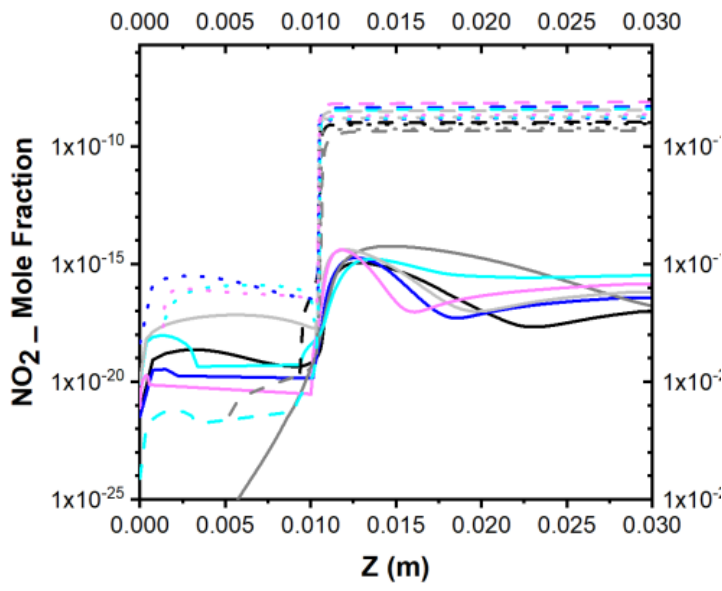

(c)

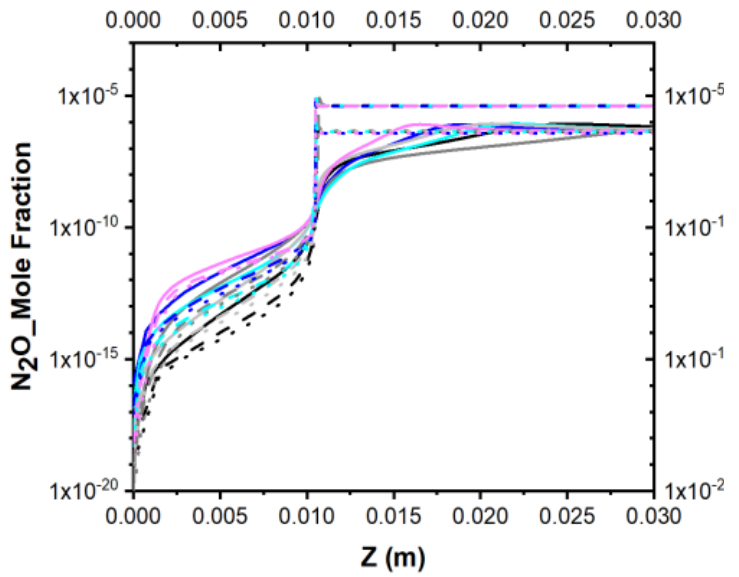

(b)

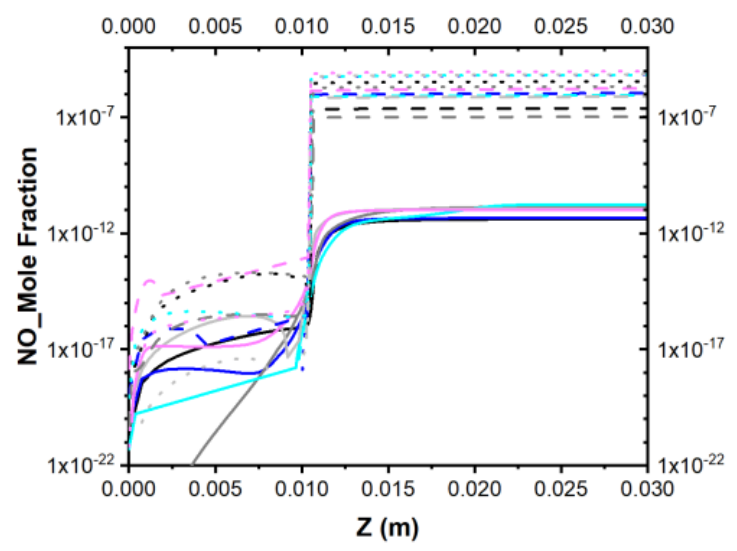

(d)

$$
\begin{aligned}
& \phi=0.25 \phi=0.75 \phi=1.2 \\
& \text { n-propanol }--\cdots \\
& \text { iso-propanol }--. . \\
& \text { n-butanol }--. \\
& \text { sec-butanol }-- \\
& \text { iso-butanol } \\
& \text { tert-butanol }
\end{aligned}
$$

Figure 16. Model prediction for the mole fraction of (a) $\mathrm{CO},(\mathbf{b}) \mathrm{NO},(\mathbf{c}) \mathrm{NO}_{2}$, and (d) $\mathrm{N}_{2} \mathrm{O}$ emissions as a function of flame length in a free flame at $860 \mathrm{~K}$ and $36 \mathrm{~atm}$ for the unburned fuel/air-mixture.

Due to the high excess air at $\phi=0.25$, the adiabatic flame temperature is below $1500 \mathrm{~K}$, which leads to low a production of $\mathrm{NO}$ (mole fraction $4 \times 10^{-12}$ to $1.7 \times 10^{-11}$ ) and $\mathrm{NO}_{2}$ $\left(1 \times 10^{-17}\right.$ to $\left.3.3 \times 10^{-16}\right)$ for all the $\mathrm{C} 3$ and $\mathrm{C} 4$ alcohols. The $\mathrm{NO}$ emissions are about one order of magnitude higher at $\phi=1.2$ compared to $\phi=0.75$, suggesting that the by 8 to $9 \%$ higher adiabatic flame temperature in the rich mixture is the predominant reason for NO formation.

Comparing the fuels, it is noticeable, that the n-alcohols tend to have lower $\mathrm{NO}$ and $\mathrm{NO}_{2}$ emissions, whereas tert-butanol, iso-propanol and iso-butanol show a higher production of nitrogen oxides. The $\mathrm{N}_{2} \mathrm{O}$ emissions of the considered fuels at $\phi=0.75$ are nearly one order of magnitude higher compared to the rich and the ultra-lean fuel/air mixtures. 
The peak mole fractions of acetylene $\left(\mathrm{C}_{2} \mathrm{H}_{2}\right)$ and diacetylene $\left(\mathrm{C}_{4} \mathrm{H}_{2}\right)$ in free flames at ultra-lean $(\phi=0.25)$, lean $(\phi=0.75)$ and rich $(\phi=1.2)$ conditions are shown in Figure 17 . Both acetylene and diacetylene production is more than halved for all the considered alcohols when increasing the air ratio from rich to lean case. Iso-butanol and tert-butanol tend to have the highest production of soot precursors. The production of soot precursors at ultra-lean conditions is very low for all fuels with $3 \times 10^{-7}$ to $2.7 \times 10^{-8}$ diacetylene, and $1.4 \times 10^{-4}$ to $1.6 \times 10^{-5}$ acetylene respectively. For both species, acetylene and diacetylene, the model predicts the highest production for the combustion of n-butanol. C3-isomers show a lower sooting tendency overall, due to the lower carbon content.

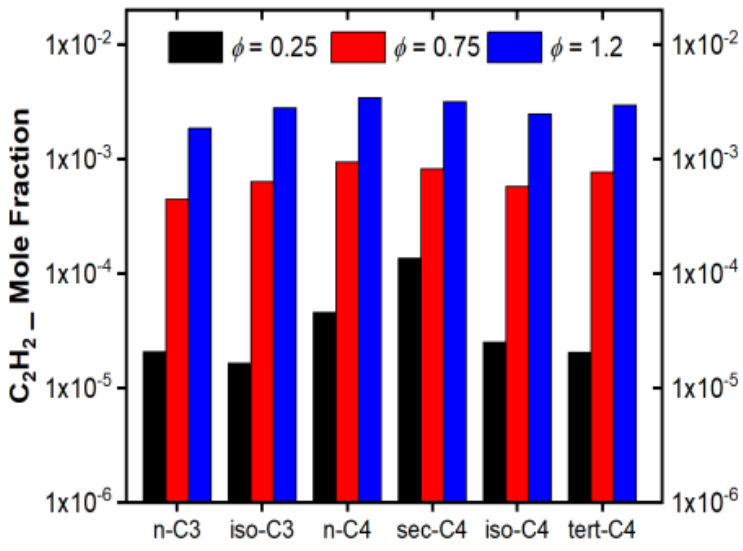

(a)

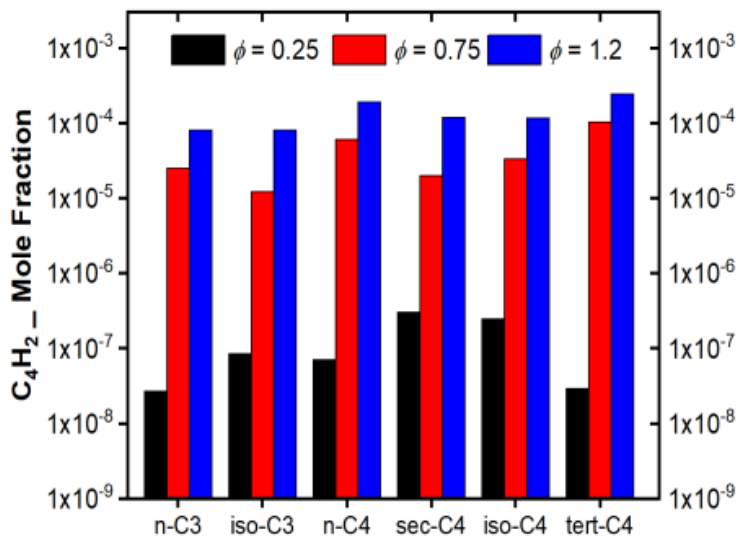

(b)

Figure 17. Model prediction for the peak value of (a) $\mathrm{C}_{2} \mathrm{H}_{2}$, and (b) $\mathrm{C}_{4} \mathrm{H}_{2}$ mole fraction a free flame at $860 \mathrm{~K}$ and 36 atm for the unburned fuel/air-mixture.

Contrary to expectations, the kinetics modeling of ignition and free flame showed that the final mole fraction of $\mathrm{N}_{2} \mathrm{O}$ is the highest at $\phi=0.75$ compared to those of at $\phi=0.25$ and 1.2 , whereas the model predicted a lower amount of $\mathrm{N}_{2} \mathrm{O}$ at $\phi=0.25$. This inconsistency may be due to the different rates of the dominant reactions at each equivalence ratio. For this reason, the $\mathrm{N}_{2} \mathrm{O}$ net rate of production (ROP) in the autoignition of tert-butanol, as an example, from time zero to the end of ignition were analyzed employing the chemical kinetic model (Figure 18).

$\mathrm{N}_{2} \mathrm{O}$ is present in 10 elementary reactions as a product or reactant in the $\mathrm{C} 4$ mechanism, whereas the decomposition of $\mathrm{N}_{2} \mathrm{O}$ to $\mathrm{N}_{2}$ and $\mathrm{O}$ in presence of third bodies, the red line in Figure 18, shows the highest rate. The negative ROP of this reaction increasing with time implies an increase in $\mathrm{N}_{2} \mathrm{O}$ as the product of the backward reaction that reaches a maximum at a specific time for each $\phi$, while this maximum is the highest at $\phi=0.75$ and lowest at $\phi=0.25$. What stands in this figure for $\phi=0.25$ is the changing the direction of the reaction after the continual decrease of ROP following the maximum point that leads to the decomposition of some $\mathrm{N}_{2} \mathrm{O}$, even though the lowest amount of $\mathrm{N}_{2} \mathrm{O}$ is produced at $\phi=0.25$. Moreover, the reaction rate for the consumption of $\mathrm{N}_{2} \mathrm{O}$ in presence of $\mathrm{CO}$ is substantial at $\phi=0.25$, whereas it is negligible at $\phi=0.75$ and 1.2. The second important reaction dominating the $\mathrm{N}_{2} \mathrm{O}$ production/consumption, particularly for $\phi=0.75$ and 1.2, is the reaction of $\mathrm{N}_{2} \mathrm{O}$ with hydroxyl radical that produces water and nitrogen. Additionally, for this reaction, the rate of the reverse reaction is higher than the forward reaction, resulting in a negative overall rate.

As a whole, the net reaction rate for the $\mathrm{N}_{2} \mathrm{O}$ production/consumption shows that at $\phi=0.75$, the highest amount of $\mathrm{N}_{2} \mathrm{O}$ produced with the maximum overall production rate of $0.0045 \mathrm{~mole} /\left(\mathrm{cm}^{3} \mathrm{~s}\right)$, while this value is less than 0.004 for $\phi=1.2$.

Despite the absolute concentration of both $\mathrm{C}_{2} \mathrm{H}_{2}$ and $\mathrm{C}_{4} \mathrm{H}_{2}$ radicals are low at lean conditions, it is worth observing the reaction pathway for their consumption and produc- 
tion. Figure 19 presents the main reaction pathways for the formation of $\mathrm{C}_{2} \mathrm{H}_{2}$ and $\mathrm{C}_{4} \mathrm{H}_{2}$ in the oxidation of tert-butanol process at the engine-related condition and $\phi=0.75$ with the C4 mechanism. The thickness of the arrows implies the rates of the specific pathway, considering the thicker the arrow, the higher the rate of reaction.

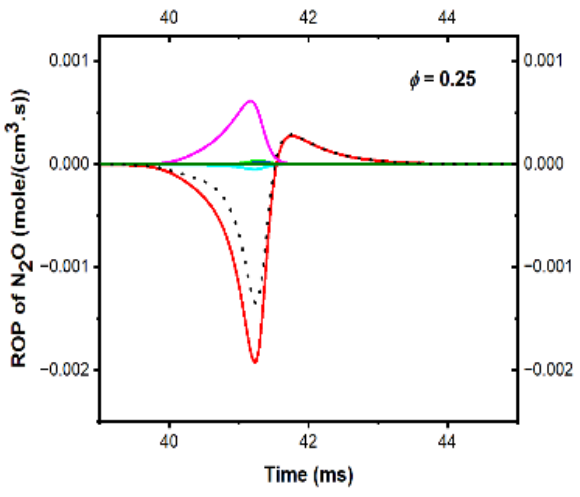

(a)

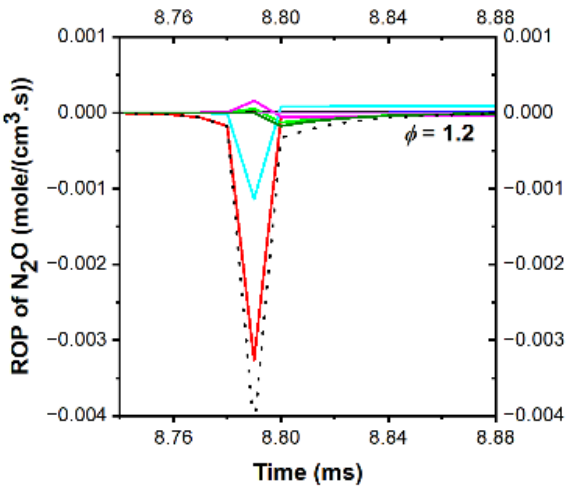

(c)

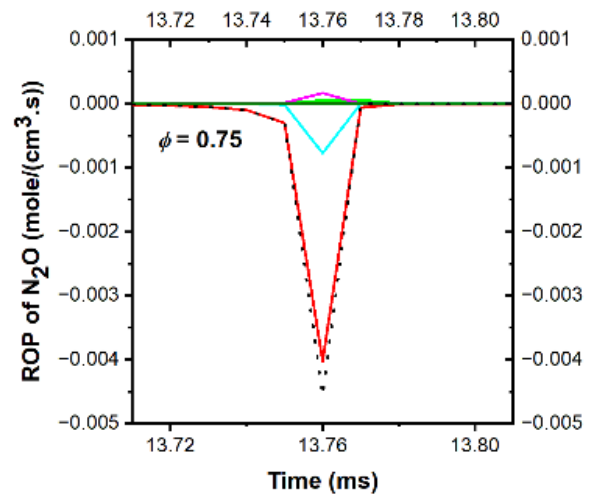

(b)

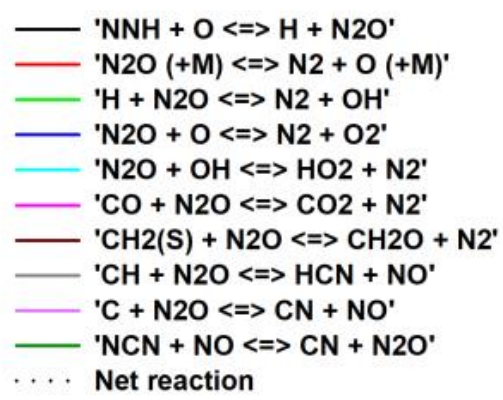

Figure 18. ROP analysis of $\mathrm{N}_{2} \mathrm{O}$ for the oxidation of tert-butanol at (a) $\phi=0.25$, (b) $\phi=0.75$ and (c) $\phi=1.2$.

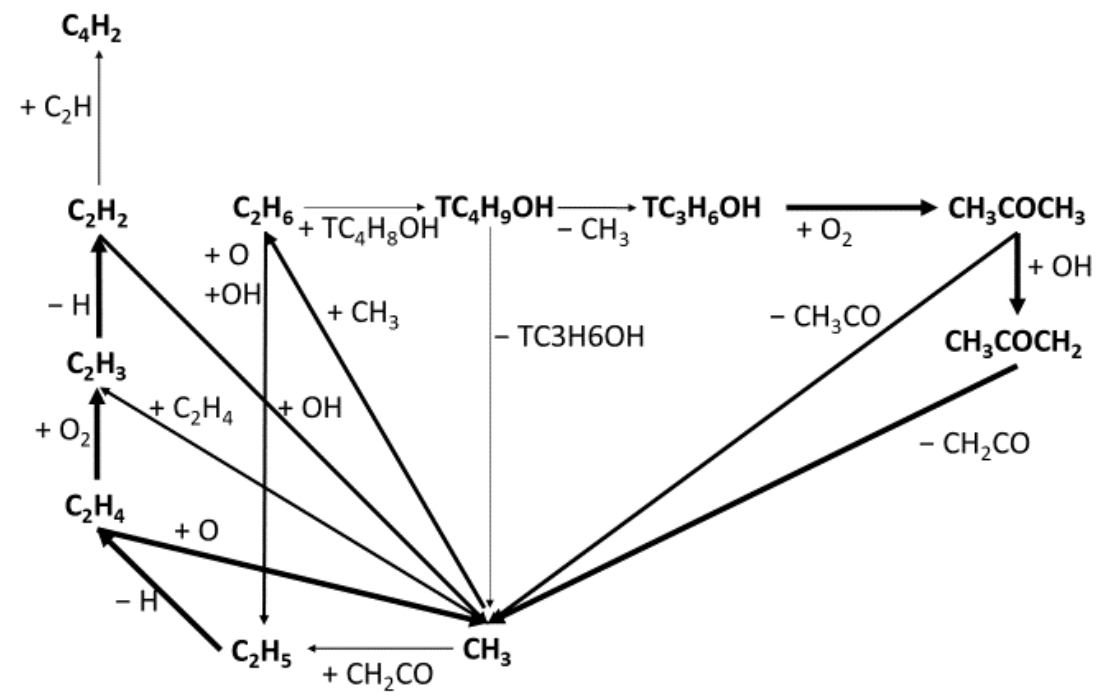

Figure 19. Reaction path diagram for tert-butanol oxidation at $860 \mathrm{~K}, 36 \mathrm{~atm}$ and $\phi=0.75$ with the C4 mechanism. 
From the beginning, the tert-butanol first splits to $\mathrm{CH}_{3}$ and tert- $\mathrm{C}_{3} \mathrm{H}_{6} \mathrm{OH}$ radicals and later tert- $\mathrm{C}_{3} \mathrm{H}_{6} \mathrm{OH}$ radical takes a leading role in the oxidation process. The formation of $\mathrm{CH}_{3}$ and then $\mathrm{C}_{2} \mathrm{H}_{6}$ from tert-butanol subsequently lead to the formation of $\mathrm{C}_{2} \mathrm{H}_{2}$ and $\mathrm{C}_{4} \mathrm{H}_{2}$ radicals. The rate of production of $\mathrm{C}_{2} \mathrm{H}_{2}$ is three orders of magnitude higher than the consumption of $\mathrm{C}_{2} \mathrm{H}_{2}$ which along with the $\mathrm{C}_{2} \mathrm{H}$ radical gives rise to $\mathrm{C}_{4} \mathrm{H}_{2}$ formation. This higher production rate of $\mathrm{C}_{2} \mathrm{H}_{2}$ than the consumption rate denotes the higher amount of $\mathrm{C}_{2} \mathrm{H}_{2}$ compared to $\mathrm{C}_{4} \mathrm{H}_{2}$ at the end of the ignition process of all fuels. Further detailed investigation of production and consumption of $\mathrm{C}_{2} \mathrm{H}_{2}$ and $\mathrm{C}_{4} \mathrm{H}_{2}$ radicals are given as follows.

Among 67 reactions that consume or produce acetylene available in our developed C4 mechanism, the ROP of 7 elementary reactions which are of greater importance is summarized in Figure 20. The reaction of $\mathrm{C}_{2} \mathrm{H}_{2}$ in presence of $\mathrm{O}$ radical plays an important role in the consumption of $\mathrm{C}_{2} \mathrm{H}_{2}$ for all $\phi$. On the contrary, the decomposition of $\mathrm{C}_{2} \mathrm{H}_{3}$ in the presence of third bodies and decomposition of $\mathrm{C}_{3} \mathrm{H}_{5}-\mathrm{S}$ is crucial in the production of $\mathrm{C}_{2} \mathrm{H}_{2}$. At lean conditions, the rate of reactions producing $\mathrm{C}_{2} \mathrm{H}_{2}$ approximately offset by those of consumption reactions gives rise to a small amount of $\mathrm{C}_{2} \mathrm{H}_{2}$ be produced.

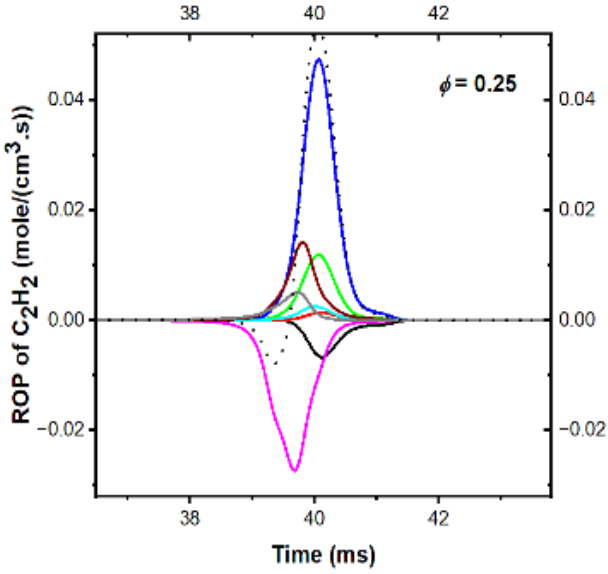

(a)

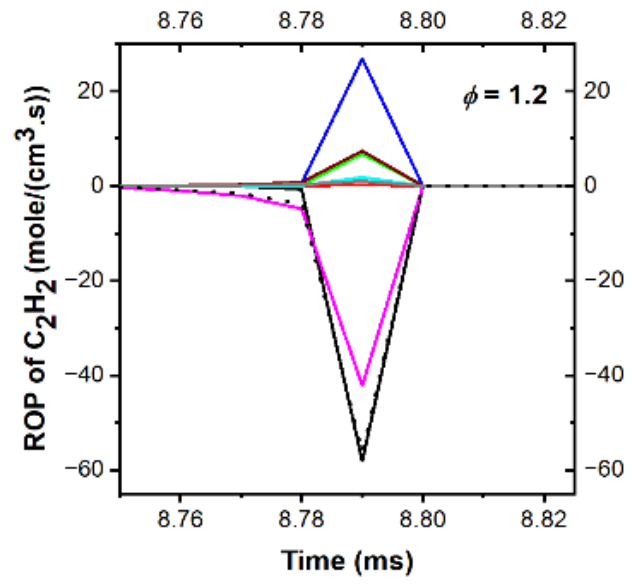

(c)

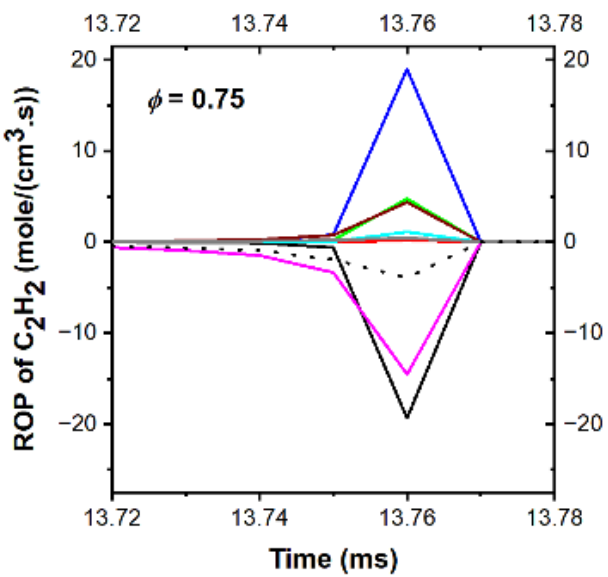

(b)

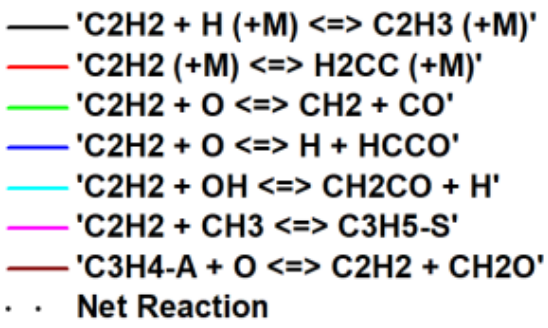

Figure 20. ROP analysis of $\mathrm{C}_{2} \mathrm{H}_{2}$ for the oxidation of tert-butanol at (a) $\phi=0.25$, (b) $\phi=0.75$ and (c) $\phi=1.2$.

In our newly developed C4 mechanism, diacetylene participates in eight elementary reactions taken from the Sarathy 2012 mechanism (Figure 21). The numerical modeling for the $\mathrm{C}_{4} \mathrm{H}_{2}$ ROP proved that reaction of diacetylene and hydroxyl radical is of greater 
significance at $\phi=0.25$, while this reaction is the third significant reaction at $\phi=0.75$ and 1.2. On the other hand, the production of $\mathrm{C}_{4} \mathrm{H}_{2}$ through the reaction between $\mathrm{C}_{2} \mathrm{H}_{2}$ and $\mathrm{C}_{2} \mathrm{H}$, and the decomposition of $\mathrm{C}_{4} \mathrm{H}_{3}-\mathrm{N}$ are more crucial at $\phi=0.75$ and 1.2 , whereas the rate of these two reactions is in the same magnitude at $\phi=0.25$ and 1.2. The reaction between $\mathrm{C}_{4} \mathrm{H}_{3}$-I and $\mathrm{H}$ plays a considerable role at $\phi=0.75$ and 1.2 with a higher rate at $\phi=1.2$, while the rate of this reaction is negligible at $\phi=0.25$.

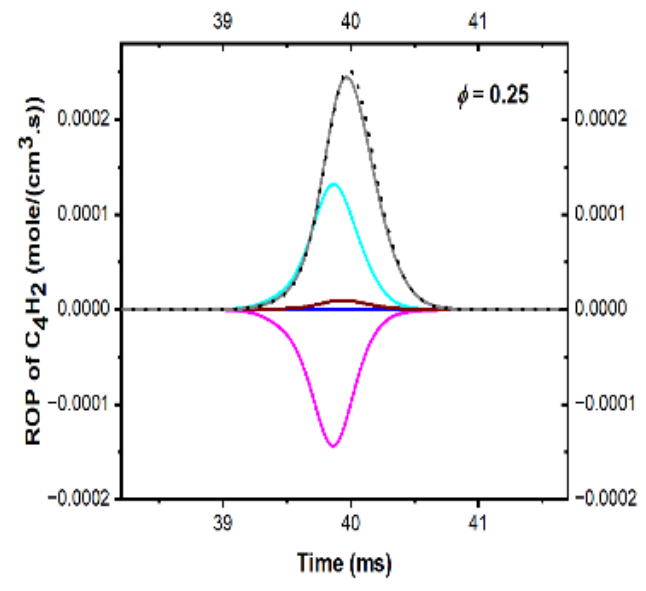

(a)

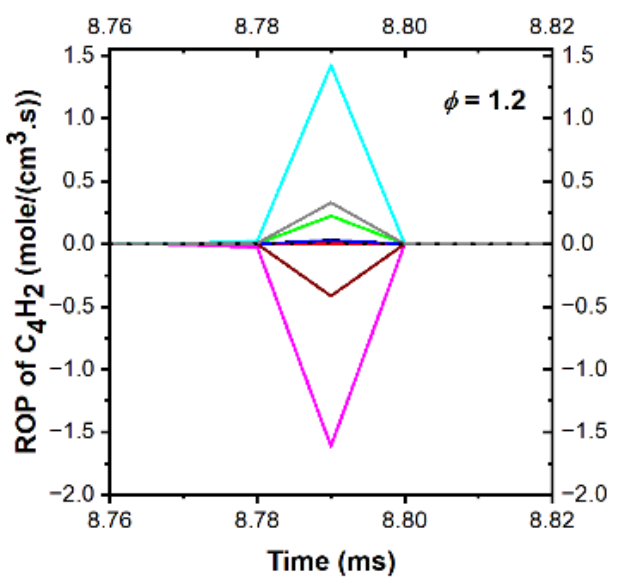

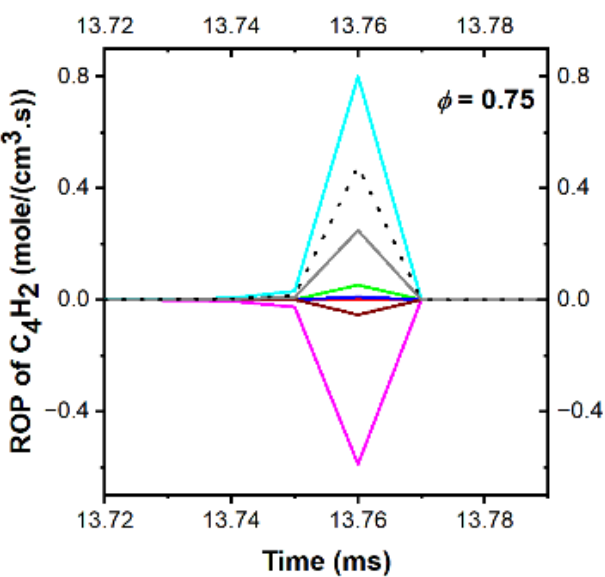

(b)

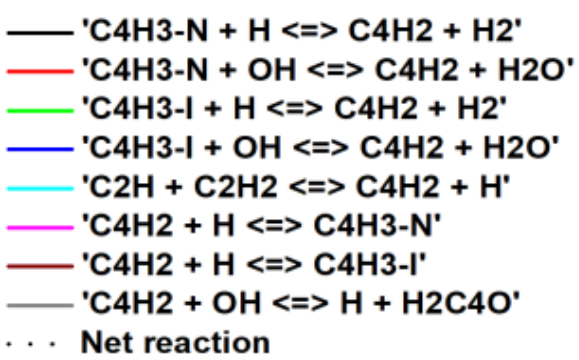

(c)

Figure 21. ROP analysis of $\mathrm{C}_{4} \mathrm{H}_{2}$ for the oxidation of tert-butanol at (a) $\phi=0.25$, (b) $\phi=0.75$ and (c) $\phi=1.2$.

\section{Conclusions}

To reach sustainable and clean future aviation, the approach is followed to replace the fossil fuel within the gas turbine engines not only by synthetically produced e-fuel (e-kerosine), as shown here, the non- $\mathrm{CO}_{2}$ emissions remain to be very high. Instead, alternative advanced e-fuels are investigated, which will possibly allow the application of the very clean lean prevaporized premixed (LPP) burning concept in future aviation engines. This requires finding advanced e-fuels with a very low tendency to early preignition during the mixing process with the heated air. For that, potential other e-fuels are investigated with long ignition delay time (IDT).

As seen from the literature review, the study concerning the combustion properties of propanol and butanol isomers at diluted fuel-lean, high-temperature, and pressure conditions is very limited. In this work, the autoignition properties of propanol isomers and butanol isomers were investigated in an HPST at temperatures of 1200-1500 K, the 
pressure of 10 bar, equivalence ratio of $0.9,0.5$, and 0.25 , and $90 \%$ dilution. According to the experimental results, no negative temperature coefficient phenomenon was observed in the investigated temperature range. The ignition delay time of all the fuels had the same negative dependence on temperature and equivalence ratio, namely, as either of the twoparameter decreases, the ignition delay time increases. The order of the reactivity among propanol and butanol isomers is consistent under all investigated conditions, namely, n-butanol > iso-butanol $\cong$ sec-butanol $>$ n-propanol $>$ iso-propanol $>$ tert-butanol.

The laminar burning velocities (LBVs) in free flame model predictions showed a similar order as observed before except for n-propanol, which has faster flame speeds than iso-butanol and sec-butanol. Due to limited comprehensive studies including all isomers of propanol and butanol, only one set of data $(343 \mathrm{~K}, 1 \mathrm{~atm}$, and equivalence ratio between 0.7 and 1.5) was used for the mechanism validation in terms of LBV.

Since the available chemical kinetic mechanism can predict IDTs and LBVs of propanol or butanol individually but show inadequate performance in the prediction of IDTs and LBVs of all propanol and butanol isomers, a modification to the Sarathy2012 mechanism in combination with the Saggese2020 mechanism has been done. The modification was validated based on the experimental data analyzed in this work in HPST, the previous investigation carried out in our group on the combustion of the targeted fuels at an intermediate temperature in RCM [39-41] and LBVs of the isomers of C3- and C4-alcohols by Veloo et al. $[34,35]$. The newly developed comprehensive mechanism, called the C4 mechanism, was employed for further numerical simulation.

The LPP conditions were estimated from the compressor equation and an overall pressure ratio of 36. As a result, in the takeoff phase of the aircraft the temperature is 860 $\mathrm{K}$ and the pressure is $36 \mathrm{~atm}$ in the mixing zone, where the liquid fuel is injected into the compressed air, prevaporizes and premixes.

The IDT is used as a guide to approximate the available time for prevaporizing and premixing with no auto-ignition. The results show that Jet-A has the highest reactivity with IDTs $<1 \mathrm{~ms}$ and therefore is least feasible for safe LPP combustion chambers, as it is most likely to auto-ignite and damage the engine. The IDTs of the objected alcohols increase by less than one order of magnitude by changing the equivalence ratio from 1.2 to 0.25 . The order of reactivity remains consistently at LPP conditions, so that tert-butanol and iso-propanol show the highest IDT, thus the lowest autoignition tendency.

Laminar burning velocities at LPP conditions give an approximation of the flashback tendency. The LBV predicted for Jet-A is more than one order of magnitude higher than the ones from the $\mathrm{C} 3$ and $\mathrm{C} 4$ alcohols. At lean conditions, the propanol and butanol isomers' LBV may be assumed to be lower than the flow velocity and therefore returns a low risk for the flashback.

From the emission point of view, it can be outlined that lean and ultra-lean conditions prevent soot emissions very well. The impact of lean conditions regarding NOx emissions is significantly for ultra-lean equivalence ratios as 0.25 , but only marginal at $\phi=0.75$.

Although the $\mathrm{C} 4$ mechanism can be used to carry out complex calculations including alcohol blends, the limitation of this mechanism is the production of soot cannot be simulated and only the soot precursors were analyzed in this study. Moreover, the large-scale kinetics mechanism causes high CPU usage resulting in high simulation time, therefore the reduction of this mechanism can speed up the simulation considerably, which needs further investigation on the oxidation of the targeted fuels for the validation of the reduced mechanism.

Supplementary Materials: The following are available online at https:/ / www.mdpi.com/article/ 10.3390 / en14175473/s1, Figure S1: IDTs of propanol and butanol isomers measured in the HPST at 10 bar and $\phi=0.25,0.5$ and 0.9. (Symbols: experimental points; Lines: model predictions), Figure S2: IDTs of propanol and butanol isomers measured in the RCM at 20 and 40 bar and $\phi=0.25,0.5$ and 0.9. (Symbols: experimental points; Lines: model predictions). 
Author Contributions: Conceptualization: F.D., R.F., S.N. and B.S.; Data curation, S.N. and P.Z.; Funding acquisition R.F. and F.D.; Investigation, L.S.; Methodology, S.N. and P.Z.; Project administration, B.S.; Software, S.N. and P.Z.; Supervision, R.F., F.D. and B.S.; Validation, S.N. and P.Z.; Writing-original draft, S.N., P.Z. and L.S.; Writing-review and editing, R.F., F.D., and B.S. All authors have read and agreed to the published version of the manuscript.

Funding: This research was funded by the Deutsche Forschungsgemeinschaft (DFG, German Research Foundation) under Germany's Excellence Strategy-EXC 2163/1- Sustainable and Energy Efficient Aviation-Project-ID 390881007.

Institutional Review Board Statement: Not applicable.

Informed Consent Statement: Not applicable.

Data Availability Statement: The data that support the findings of this study are available on request from the corresponding author, Solmaz Nadiri.

Conflicts of Interest: The authors declare no conflict of interest.

\section{References}

1. Sustainable Aviation Fuels. Available online: https://www.easa.europa.eu/eaer/topics/sustainable-aviation-fuels (accessed on 10 July 2021).

2. Lefebvre, A.H.; Ballal, D.R. Gas Turbine Combustion: Alternative Fuels and Emissions; CRC Press: Boca Raton, FL, USA, 2010; ISBN 1420086057.

3. European Green Deal: Commission Proposes Transformation of EU Economy and Society to Meet Climate Ambitions. Available online: https:/ / ec.europa.eu/commission/presscorner/detail/en/IP_21_3541 (accessed on 10 July 2021).

4. Skov, I.R.; Schneider, N.; Schweiger, G.; Schöggl, J.-P.; Posch, A. Power-to-X in Denmark: An Analysis of Strengths, Weaknesses, Opportunities and Threats. Energies 2021, 14, 913. [CrossRef]

5. Albo, J.; Alvarez-Guerra, M.; Castaño, P.; Irabien, A. Towards the Electrochemical Conversion of Carbon Dioxide into Methanol. Green Chem. 2015, 17, 2304-2324. [CrossRef]

6. Rego de Vasconcelos, B.; Lavoie, J.-M. Recent Advances in Power-to-X Technology for the Production of Fuels and Chemicals. Front. Chem. 2019, 7, 392. [CrossRef] [PubMed]

7. Bauen, A.; Bitossi, N.; German, L.; Harris, A.; Leow, K. Sustainable Aviation Fuels: Status, Challenges and Prospects of Drop-in Liquid Fuels, Hydrogen and Electrification in Aviation. Johns. Matthey Technol. Rev. 2020, 64, 263-278.

8. Lee, D.S.; Fahey, D.W.; Forster, P.M.; Newton, P.J.; Wit, R.C.N.; Lim, L.L.; Owen, B.; Sausen, R. Aviation and Global Climate Change in the 21st Century. Atmos. Environ. 2009, 43, 3520-3537. [CrossRef]

9. Lee, D.S.; Fahey, D.W.; Skowron, A.; Allen, M.R.; Burkhardt, U.; Chen, Q.; Doherty, S.J.; Freeman, S.; Forster, P.M.; Fuglestvedt, J. The Contribution of Global Aviation to Anthropogenic Climate Forcing for 2000 to 2018. Atmos. Environ. $2021,244,117834$. [CrossRef] [PubMed]

10. Goldmann, A.; Sauter, W.; Oettinger, M.; Kluge, T.; Schröder, U.; Seume, J.R.; Friedrichs, J.; Dinkelacker, F. A Study on Electrofuels in Aviation. Energies 2018, 11, 392. [CrossRef]

11. Lefebvre, A.H.; Freeman, W.; Cowell, L. Spontaneous Ignition Delay Characteristics of Hydrocarbon Fuel-Air Mixtures; Purdue University, School of Mechanical Engineering: West Lafayette, IN, USA, 1986.

12. Marek, C.J.; Papathakos, L.; Verbulecz, P. Preliminary Studies of Autoignition and Flashback in a Premixing-Prevaporizing Flame Tube Using Jet-a Fuel at Lean Equivalence Ratios. Contract 1977, 505, 3.

13. Harvey, B.G.; Meylemans, H.A. The Role of Butanol in the Development of Sustainable Fuel Technologies. J. Chem. Technol. Biotechnol. 2011, 86, 2-9. [CrossRef]

14. Nair, P.; Meenakshi, H.N. Review on the Synthesis, Performance and Trends of Butanol: A Cleaner Fuel Additive for Gasoline. Int. J. Ambient Energy 2021, 1-17. [CrossRef]

15. Mourad, M.; Mahmoud, K.R.M. Performance Investigation of Passenger Vehicle Fueled by Propanol/Gasoline Blend According to a City Driving Cycle. Energy 2018, 149, 741-749. [CrossRef]

16. Kaisan, M.U.; Yusuf, L.O.; Ibrahim, I.U.; Abubakar, S.; Narayan, S. Effects of Propanol and Camphor Blended with Gasoline Fuel on the Performance and Emissions of a Spark Ignition Engine. ACS Omega 2020, 5, 26454-26462. [CrossRef] [PubMed]

17. Moss, J.T.; Berkowitz, A.M.; Oehlschlaeger, M.A.; Biet, J.; Warth, V.; Glaude, P.-A.; Battin-Leclerc, F. An Experimental and Kinetic Modeling Study of the Oxidation of the Four Isomers of Butanol. J. Phys. Chem. A 2008, 112, 10843-10855. [CrossRef]

18. Montero, E.A.; Aguilar, F.; Muñoz-Rujas, N.; Alaoui, F.E.M. Thermodynamic Properties of Propanol and Butanol as Oxygenate Additives to Biofuels. Front. Bioenergy Biofuels 2017, 363-389. [CrossRef]

19. Yan, Y.; Dang, L.; Deng, Y.; Li, J.; Zhao, J. Experimental Study of Flow Dynamics and Fuel Spray Characteristics in Lean Premixed Prevaporized Combustor. Fuel 2015, 144, 197-204. [CrossRef]

20. Maier, G.; Wittig, S. Fuel Preparation and Emission Characteristics of a Pressure Loaded LPP Combustor. In Proceedings of the 30th Fluid Dynamics Conference, Norfolk, VA, USA, 28 June-1 July 1999; p. 3774. 
21. Imamura, A.; Yoshida, M.; Kawano, M.; Aruga, N.; Nagata, Y.; Kawagishi, M. Research and Development of a LPP Combustor with Swirling Flow for Low NO (X). In Proceedings of the 37th Joint Propulsion Conference and Exhibit, Salt Lake City, UT, USA, 8-11 July 2001; p. 3311.

22. Gokulakrishnan, P.; Ramotowski, M.J.; Gaines, G.; Fuller, C.; Joklik, R.; Eskin, L.D.; Klassen, M.S.; Roby, R.J. A Novel Low Nox Lean, Premixed, and Prevaporized Combustion System for Liquid Fuels. J. Eng. Gas Turbines Power 2008, 130, 051501. [CrossRef]

23. Goldmann, A.; Dinkelacker, F. Experimental Investigation and Modeling of Boundary Layer Flashback for Non-Swirling Premixed Hydrogen/Ammonia/Air Flames. Combust. Flame 2021, 226, 362-379. [CrossRef]

24. Johnson, M.V.; Goldsborough, S.S.; Serinyel, Z.; O’Toole, P.; Larkin, E.; O’Malley, G.; Curran, H.J. A Shock Tube Study of N-and Iso-Propanol Ignition. Energy Fuels 2009, 23, 5886-5898. [CrossRef]

25. Bourque, G.; Healy, D.; Curran, H.; Zinner, C.; Kalitan, D.; de Vries, J.; Aul, C.; Petersen, E. Ignition and Flame Speed Kinetics of Two Natural Gas Blends with High Levels of Heavier Hydrocarbons. J. Eng. Gas Turbines Power 2010, 132, 021504. [CrossRef]

26. Man, X.; Tang, C.; Zhang, J.; Zhang, Y.; Pan, L.; Huang, Z.; Law, C.K. An Experimental and Kinetic Modeling Study of N-Propanol and i-Propanol Ignition at High Temperatures. Combust. Flame 2014, 161, 644-656. [CrossRef]

27. Sarathy, S.M.; Vranckx, S.; Yasunaga, K.; Mehl, M.; Oßwald, P.; Metcalfe, W.K.; Westbrook, C.K.; Pitz, W.J.; Kohse-Höinghaus, K.; Fernandes, R.X. A Comprehensive Chemical Kinetic Combustion Model for the Four Butanol Isomers. Combust. Flame 2012, 159, 2028-2055. [CrossRef]

28. Frassoldati, A.; Cuoci, A.; Faravelli, T.; Niemann, U.; Ranzi, E.; Seiser, R.; Seshadri, K. An Experimental and Kinetic Modeling Study of N-Propanol and Iso-Propanol Combustion. Combust. Flame 2010, 157, 2-16. [CrossRef]

29. Gong, J.; Zhang, S.; Cheng, Y.; Huang, Z.; Tang, C.; Zhang, J. A Comparative Study of N-Propanol, Propanal, Acetone, and Propane Combustion in Laminar Flames. Proc. Combust. Inst. 2015, 35, 795-801. [CrossRef]

30. Weber, B.W.; Sung, C.-J. Comparative Autoignition Trends in Butanol Isomers at Elevated Pressure. Energy Fuels 2013, 27, 1688-1698. [CrossRef]

31. Karwat, D.M.A.; Wagnon, S.W.; Teini, P.D.; Wooldridge, M.S. On the Chemical Kinetics of N-Butanol: Ignition and Speciation Studies. J. Phys. Chem. A 2011, 115, 4909-4921. [CrossRef] [PubMed]

32. Heufer, K.A.; Fernandes, R.X.; Olivier, H.; Beeckmann, J.; Röhl, O.; Peters, N. Shock Tube Investigations of Ignition Delays of N-Butanol at Elevated Pressures between 770 and 1250 K. Proc. Combust. Inst. 2011, 33, 359-366. [CrossRef]

33. Stranic, I.; Chase, D.P.; Harmon, J.T.; Yang, S.; Davidson, D.F.; Hanson, R.K. Shock Tube Measurements of Ignition Delay Times for the Butanol Isomers. Combust. Flame 2012, 159, 516-527. [CrossRef]

34. Veloo, P.S.; Egolfopoulos, F.N. Flame Propagation of Butanol Isomers/Air Mixtures. Proc. Combust. Inst. 2011, 33, 987-993. [CrossRef]

35. Veloo, P.S.; Egolfopoulos, F.N. Studies of N-Propanol, Iso-Propanol, and Propane Flames. Combust. Flame 2011, 158, 501-510. [CrossRef]

36. Saggese, C.; Thomas, C.M.; Wagnon, S.W.; Kukkadapu, G.; Cheng, S.; Kang, D.; Goldsborough, S.S.; Pitz, W.J. An Improved Detailed Chemical Kinetic Model for C3-C4 Linear and Iso-Alcohols and Their Blends with Gasoline at Engine-Relevant Conditions. Proc. Combust. Inst. 2021, 38, 415-423. [CrossRef]

37. McGillen, M.R.; Baasandorj, M.; Burkholder, J.B. Gas-Phase Rate Coefficients for the OH+ n-, i-, s-, and t-Butanol Reactions Measured between 220 and 380 K: Non-Arrhenius Behavior and Site-Specific Reactivity. J. Phys. Chem. A 2013, 117, 4636-4656. [CrossRef] [PubMed]

38. Mittal, G.; Burke, S.M.; Davies, V.A.; Parajuli, B.; Metcalfe, W.K.; Curran, H.J. Autoignition of Ethanol in a Rapid Compression Machine. Combust. Flame 2014, 161, 1164-1171. [CrossRef]

39. Wang, Q. Investigation on the Ignition Properties of Propanol and Butanol Isomers under Fuel Lean Conditions. Master's Thesis, Technische Universität Braunschweig, Braunschweig, Germany, 2021.

40. Laguna, A.G. Investigation on the Ignition Delay Time of Butanol Fuels for Aviation Application. Bachelor's Thesis, Technische Universität Braunschweig, Braunschweig, Germany, 2020.

41. Wang, Q.; Laguna, A.G.; He, X.; Shu, B.; Li, L. Investigation on the Ignition Properties of 1-Propanol and 1-Butanol under Fuel-Lean Conditions; SAE Technical Paper; SAE: Warrendale, PA, USA, 2021.

42. Nishida, M. Shock tubes. In Handbook of Shock Waves; Elsevier: Amsterdam, The Netherlands, 2001; pp. 553-585.

43. Goodwin, D.G.; Moffat, H.K.; Speth, R.L. Cantera: An Object-Oriented Software Toolkit for Chemical Kinetics, Thermodynamics, and Transport Processes. Comput. Sci. 2009. [CrossRef]

44. Nadiri, S.; Agarwal, S.; He, X.; Kühne, U.; Fernandes, R.; Shu, B. Development of the Chemical Kinetic Mechanism and Modeling Study on the Ignition Delay of Liquefied Natural Gas (LNG) at Intermediate to High Temperatures and High Pressures. Fuel 2021, 302, 121137. [CrossRef]

45. Wu, Y.; Yang, M.; Tang, C.; Liu, Y.; Zhang, P.; Huang, Z. Promoting “Adiabatic Core” Approximation in a Rapid Compression Machine by an Optimized Creviced Piston Design. Fuel 2019, 251, 328-340. [CrossRef]

46. Van Geem, K.M.; Pyl, S.P.; Marin, G.B.; Harper, M.R.; Green, W.H. Accurate High-Temperature Reaction Networks for Alternative Fuels: Butanol Isomers. Ind. Eng. Chem. Res. 2010, 49, 10399-10420. [CrossRef]

47. Sarathy, S.M.; Oßwald, P.; Hansen, N.; Kohse-Höinghaus, K. Alcohol Combustion Chemistry. Prog. Energy Combust. Sci. 2014, 44, 40-102. [CrossRef] 
48. Cheng, S.; Kang, D.; Goldsborough, S.S.; Saggese, C.; Wagnon, S.W.; Pitz, W.J. Experimental and Modeling Study of C2-C4 Alcohol Autoignition at Intermediate Temperature Conditions. Proc. Combust. Inst. 2021, 38, 709-717. [CrossRef]

49. Bugler, J.; Marks, B.; Mathieu, O.; Archuleta, R.; Camou, A.; Grégoire, C.; Heufer, K.A.; Petersen, E.L.; Curran, H.J. An Ignition Delay Time and Chemical Kinetic Modeling Study of the Pentane Isomers. Combust. Flame 2016, 163, 138-156. [CrossRef]

50. The Master Chemical Mechanism. Available online: http:/ / mcm.york.ac.uk (accessed on 10 July 2021).

51. Senosiain, J.P.; Klippenstein, S.J.; Miller, J.A. Reaction of Ethylene with Hydroxyl Radicals: A Theoretical Study. J. Phys. Chem. A 2006, 110, 6960-6970. [CrossRef] [PubMed]

52. Dooley, S.; Burke, M.P.; Chaos, M.; Stein, Y.; Dryer, F.L.; Zhukov, V.P.; Finch, O.; Simmie, J.M.; Curran, H.J. Methyl Formate Oxidation: Speciation Data, Laminar Burning Velocities, Ignition Delay Times, and a Validated Chemical Kinetic Model. Int. J. Chem. Kinet. 2010, 42, 527-549. [CrossRef]

53. Glarborg, P.; Miller, J.A.; Ruscic, B.; Klippenstein, S.J. Modeling Nitrogen Chemistry in Combustion. Prog. Energy Combust. Sci. 2018, 67, 31-68. [CrossRef]

54. Braeunling, W.J.G. Turbojet Engines. Fundamentals, Aero Thermodynamics, Ideal and Real Cycle Processes, Thermal Turbo Engines, Components, Emissions and Systems. In Flugzeugtriebwerke. Grundlagen, Aero-Thermodynamik, Ideale und Reale Kreisprozesse, Thermische Turbomaschinen, Komponenten, Emissionen und Systeme; Springer: Berlin/Heidelberg, Germany, 2009; pp. 859-972. [CrossRef]

55. Honnet, S.; Seshadri, K.; Niemann, U.; Peters, N. A Surrogate Fuel for Kerosene. Proc. Combust. Inst. 2009, 32, 485-492. [CrossRef]

56. Omidvarborna, H.; Kumar, A.; Kim, D.-S. Recent Studies on Soot Modeling for Diesel Combustion. Renew. Sustain. Energy Rev. 2015, 48, 635-647. [CrossRef]

57. Drakon, A.; Eremin, A.; Mikheyeva, E.; Shu, B.; Fikri, M.; Schulz, C. Soot Formation in Shock-Wave-Induced Pyrolysis of Acetylene and Benzene with H2, O2, and CH4 Addition. Combust. Flame 2018, 198, 158-168. [CrossRef] 